\title{
Article \\ Damage Pattern Recognition and Crack Propagation Prediction for Crumb Rubber Concrete Based on Acoustic Emission Techniques
}

\author{
Jianjie Sun ${ }^{1}$, Xi Chen ${ }^{1}$, Zhengwu Fu ${ }^{2, *}$ and Giuseppe Lacidogna ${ }^{3}$ (I) \\ 1 School of Civil Engineering, Tianjin University, Tianjin 300350, China; sunjianjie2021@sina.cn (J.S.); \\ crislynchen@tju.edu.cn (X.C.) \\ 2 Department of Civil Engineering, Tsinghua University, Beijing 100084, China \\ 3 Department of Structural, Geotechnical and Building Construction, Politecnico di Torino, 10129 Turin, Italy; \\ giuseppe.lacidogna@polito.it \\ * Correspondence: fuzw20@mails.tsinghua.edu.cn
}

check for

updates

Citation: Sun, J.; Chen, X.; Fu, Z.; Lacidogna, G. Damage Pattern Recognition and Crack Propagation Prediction for Crumb Rubber Concrete Based on Acoustic Emission Techniques. Appl. Sci. 2021, 11, 11476. https://doi.org/10.3390/ app112311476

Academic Editor: Dimitrios G. Aggelis

Received: 28 October 2021 Accepted: 1 December 2021 Published: 3 December 2021

Publisher's Note: MDPI stays neutral with regard to jurisdictional claims in published maps and institutional affiliations.

Copyright: (c) 2021 by the authors. Licensee MDPI, Basel, Switzerland. This article is an open access article distributed under the terms and conditions of the Creative Commons Attribution (CC BY) license (https:/ / creativecommons.org/licenses/by/ $4.0 /)$.

\begin{abstract}
In this study, the clustering method of the concrete matrix rupture and rubber fracture damages as well as the prediction of the ultimate load of crumb rubber concrete using the acoustic emission (AE) technique were investigated. The loading environment of the specimens was a four-point bending load. Six clustering methods including k-means, fuzzy c-means (FCM), selforganizing mapping (SOM), Gaussian mixture model (GMM), hierarchical model, and density peak clustering method were analyzed; the results illustrated that the density peak clustering has the best performance. Next, the optimal clustering algorithm was used to cluster AE signals so as to study the evolution behavior of different damage modes, and the ultimate load of crumb rubber concrete was predicted by an artificial neural network. The results indicated that the combination of AE techniques and appropriate clustering methods such as the density peak clustering method and the artificial neural network could be used as a practical tool for structural health monitoring of crumb rubber concrete.
\end{abstract}

Keywords: acoustic emission; crumb rubber concrete; damage pattern recognition; clustering methods; artificial neural network

\section{Introduction}

In recent years, the production of automobiles has led to the accumulation of numerous waste tires that are difficult to dispose of, resulting in a large amount of space occupied and a high fire hazard. The impact of waste tires on the environment and how to effectively deal with them has become an important issue. Therefore, scholars in different fields have proposed several methods to recycle waste tires. In addition to the method of retreading and reusing [1], waste tires can also be converted into other degradable or usable polymeric materials through a series of chemical methods [2]. Gnanaraj et al. [3] pyrolyzed waste tires and applied the products to energy storage devices such as batteries. Derakhshan et al. [4] found that in wastewater treatment systems, the use of waste tires as carriers of organisms is a promising application. Recently, in the direction of civil engineering, the application of grinding waste rubber tires into particles as aggregates has become increasingly widespread [5-12]. Many scholars have investigated the mechanical properties of rubber concrete. According to the experimental results, they have found that the addition of rubber particles has significantly improved the ductility and durability of the concrete, but it results in a significant decrease in strength [13-17]. Based on the current urgency of finding ways to improve strength defects and increasing the recycling rate of waste tires, scholars in related fields have stimulated in-depth research. Follow-up scholars have also studied the fatigue and impermeability behaviors of rubber concrete [18-22]. Currently, crumb rubber concrete has been widely used in tennis courts, park areas, and bridge road 
constructions. Therefore, it is important to monitor the structure of these materials to avoid large losses due to large damage inside or outside the structure. For the study of material microcracking and fracture monitoring methods, Joosten et al. [23] proposed a new computational method for the simulation of mesh division of composite materials, which allows accurate prediction of crack propagation and fracture load when damage occurs in the material. Wu et al. [24] proposed a damage model for describing material fracture, which achieves the adaptive and capture of arbitrary crack propagation in solid materials. Lin et al. [25] analyzed the connection between mechanical properties and waveforms and frequencies of four rocks during fracture to improve the accuracy of crack prediction in rocks. Recently, in order to understand the development of microcracks and the monitoring of fracture-causing behaviors, $\mathrm{Xu}$ et al. [26] have conducted experimental studies based on acoustic emission (AE) technology.

For crumb rubber concrete, there have been some studies on its microcrack and fracture characteristics [27-31], but there are few studies on the monitoring of microcrack propagation and fracture behavior under different damage modes [32-34]. Hence, if the acoustic emission signals of the microcracks at various stages in different modes can be monitored and a reasonable analysis made, it will bring benefits to practical engineering applications. For this reason, this paper used AE technology to conduct damage monitoring research on crumb rubber concrete. To investigate the different damage patterns of crumb rubber concrete under a four-point bending test, it is critical to categorize different $\mathrm{AE}$ signals. In recent years, a variety of different clustering methods have been adopted for the classification of AE signals obtained in the damage and failure process of concrete materials [35-39]. Although the types of these methods have increased, their inherent limitations have not been studied in depth. At the same time, no one used the clustering method to classify the AE signals for crumb rubber concrete. Although some researchers used the k-means clustering method to make a good distinction between the tension mode and the shear mode, the acoustic emission data of crumb rubber concrete are relatively discrete, and the k-means clustering method has limitations [40]. Therefore, the acoustic emission signal classification performance of different clustering methods needs to be analyzed and selected so as to combine acoustic emission technology to get a dependable and accurate structural health monitoring system. At the same time, a simple and efficient method is needed to predict the failure loads of the crumb rubber concrete by monitoring the crack development in concrete engineering using acoustic emission techniques. While moving ahead with computer technology, the artificial neural network algorithm has emerged. By training a large number of input data, an output result can be obtained, and by comparing it with the real value, it can be found that the calculation result is relatively reliable [41].

The research of this paper consists of three main parts: firstly, six clustering methods for analyzing AE signals are introduced in Section 2, including k-means, FCM, GMM, SOM, hierarchical model, and density peak clustering; secondly, the optimal clustering method (density peak clustering) is derived by comparative analysis in Section 3.1 and used to identify damage patterns of crumb rubber concrete; finally, in Section 3.2, the artificial neural network algorithm with input data as acoustic emission parameters is used in this paper to predict the ultimate load of crumb rubber concrete for the first time.

\section{Materials and Methods}

\subsection{Materials and Apparatus}

In the four-point bending test, the raw materials of the specimens included ordinary Portland cement, sand, coarse aggregate, and rubber crumb, among which the maximum particle size of coarse aggregate was $20 \mathrm{~mm}$, and the particle size of rubber crumb was between 1 and $2 \mathrm{~mm}$. The mixing ratio of the respective components can be found from our previous work [42]. The content of crumb rubber was divided into four groups of $0 \%$, $5 \%, 10 \%$, and $15 \%$ (according to the principle of volume percentage method). The size of the specimen was $400 \times 100 \times 100 \mathrm{~mm}$. The four sets of specimens were all designed to 
C30 compressive strength level, which is between 35 and $45 \mathrm{MPa}$. Figure 1 and Table 1 show the specific information on the location of the crumb rubber concrete specimen and acoustic emission sensors.
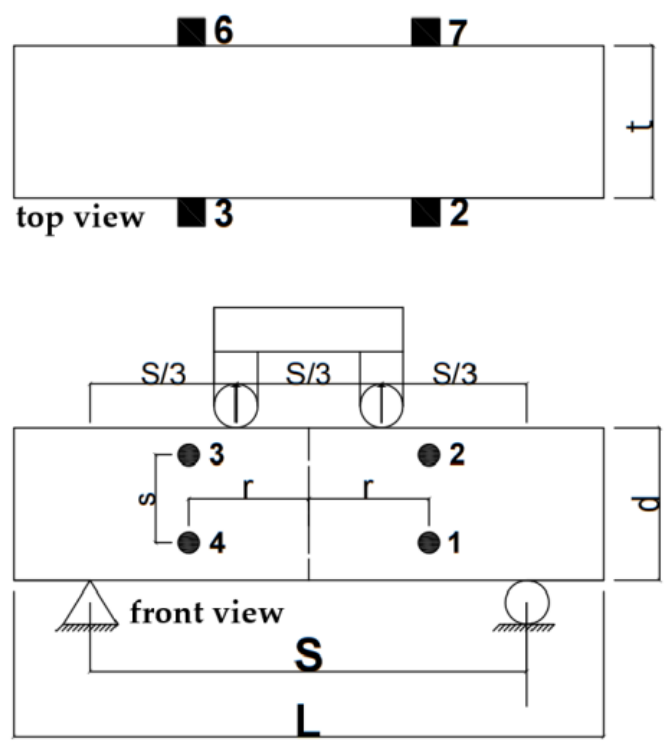

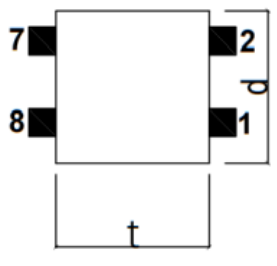

right side view

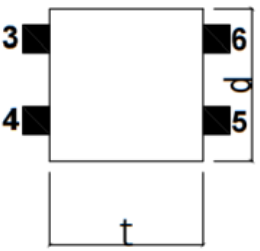

left side view

Figure 1. Configuration of the four-point bending specimen and sensors.

Table 1. Specific dimensions of the specimen and sensors.

\begin{tabular}{cccccc}
\hline & \multicolumn{2}{c}{ Specimen Size (mm) } & \multicolumn{2}{c}{ Sensor Position (mm) } \\
\hline Span (S) & Length (L) & Depth (d) & Thickness (t) & r & s \\
\hline 300 & 400 & 100 & 100 & 80 & 60 \\
\hline
\end{tabular}

For the apparatus in this test (Table 2), the $100 \mathrm{kN}$ range of electronic universal testing machine and the Micro-II Digital AE System were adopted (Figure 2a). R6 $\alpha$ resonanttype sensors were used. In order to ensure that the sensors were absolutely adhered closely to the surface of the specimen, a couplant was used and fixed with a specific fixture (Figure $2 \mathrm{~b}$ ). The threshold for acoustic emission detection was set to $40 \mathrm{~dB}$ and the loading rate of the specimen was $0.167 \mathrm{kN} / \mathrm{s}$. After setting-up the test apparatus, the processes of data acquisition are: first, during the four-point bending load, the crumb rubber concrete specimen generates internal cracks, thus forming stress waves (AE source); second, the AE sensors collect the propagated AE stress waves and convert them; third, the preamplifier amplifies the AE signals, thus ensuring the appropriate signal strength; fourth, the AE signals are stored and analyzed by the data acquisition system; and, finally, the AE characteristic parameters obtained are analyzed and studied, such as hit, amplitude, count, duration, etc. In addition, the multichannel monitoring system $\mathrm{AE}^{\mathrm{win}}$ was used as the software for AE signal acquisition and analysis, and the Matlab 10 Neural Network Toolbox was used for subsequent processing of the data. 
Table 2. Information on test apparatus.

\begin{tabular}{|c|c|c|c|}
\hline Name & Number & Function & Specification \\
\hline $\begin{array}{l}\text { Micro-II Digital AE } \\
\text { System }\end{array}$ & 1 & $\begin{array}{l}\text { Processing } \\
\text { AE signals }\end{array}$ & $\begin{array}{l}\text { Data acquisition and transfer } \\
\text { efficiency: } 40 \mathrm{MB} / \mathrm{s} ; \\
\text { Filter bandwidth: } 3 \mathrm{kHz} \text { to } \\
3 \mathrm{MHz} \text {. }\end{array}$ \\
\hline R6 $\alpha$ AE sensor & 8 & $\begin{array}{l}\text { Collecting } \\
\text { AE signals }\end{array}$ & $\begin{array}{l}\text { Peak sensitivity: } 75 \mathrm{~dB} \text { with } \\
\text { reference } 1 \mathrm{~V} /(\mathrm{m} / \mathrm{s}) ; \\
\text { Working temperature range: } \\
\quad-65 \text { to } 177^{\circ} \mathrm{C} ; \\
\text { Operating frequency: } \\
\quad 35-100 \mathrm{kHz} \text {. }\end{array}$ \\
\hline AE preamplifier & 8 & $\begin{array}{l}\text { Amplify } \\
\text { AE signals }\end{array}$ & Model: $2 / 4 / 6$ preamplifier \\
\hline $\begin{array}{l}\text { Electronic universal } \\
\text { testing machine }\end{array}$ & 1 & $\begin{array}{l}\text { Complete four-point } \\
\text { bending load }\end{array}$ & Capacity: $100 \mathrm{kN}$ \\
\hline Computer & 2 & $\begin{array}{l}\text { Record AE data and } \\
\text { loading data }\end{array}$ & \\
\hline Data cable & several & $\begin{array}{c}\text { Transmitting } \\
\text { AE signals }\end{array}$ & \\
\hline
\end{tabular}

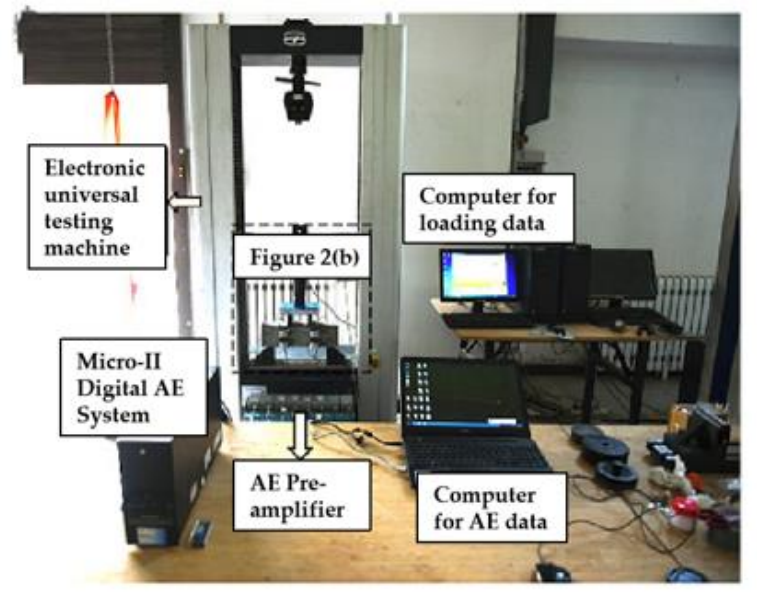

(a)

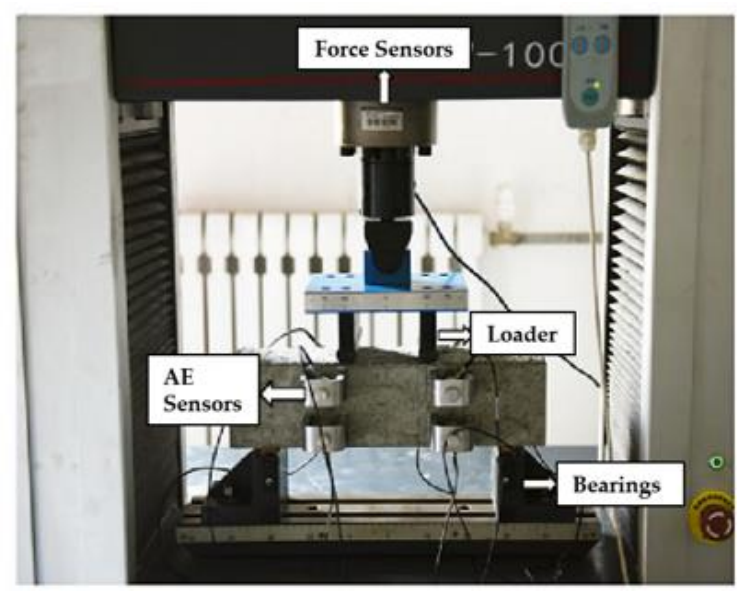

(b)

Figure 2. (a) AE experimental equipment and (b) labeled image of the four-point bending test.

\subsection{Introduction to Common Clustering Methods}

This section introduces five common clustering methods including k-means, fuzzy c-means (FCM), Gaussian mixture model (GMM), self-organizing mapping (SOM), and hierarchical model clustering to analyze acoustic emission signals. The following five clustering methods are introduced separately:

(1) K-means clustering:

The main steps of the k-means clustering are: first, the number of clustering categories $\mathrm{k}$ ( $\mathrm{k}$ cluster centers) is artificially determined, and then the similarity between each object and the cluster center are analyzed according to the distance function, and the sample points are classified into the most similar clusters. Next, the centroid of each cluster (the cluster center) is recalculated and this process is repeated until the centroid no longer changes. There are two phases of the k-means clustering algorithm [40]: 
(a) Distribution phase: Use the nearest cluster center to assign each datum to the same cluster.

$$
C_{\mathrm{i}}{ }^{(t)}=\left\{A_{n}:\left\|A_{n}-m_{i}{ }^{(t)}\right\|^{2} \leq\left\|A_{n}-m_{j}{ }^{(t)}\right\|^{2} \forall j, 1 \leq j \leq k\right\}
$$

among them $C_{\mathrm{i}}^{(t)}$ is the cluster $i, m_{\mathrm{i}}{ }^{(t)}$ is the center of cluster $i$, and $A_{n}$ represents the data points.

(b) Update phase: Recalculate the cluster center and treat it as the average of the whole cluster.

$$
m_{i}^{(t+1)}=\frac{1}{\mid C_{i}^{(t) \mid}} \sum_{A_{j} \in C_{i}(t)} A_{j}
$$

Next, iterate through the above phases until the cluster no longer changes. Due to the initial randomly selected clustering center playing a vital role on the results of the entire calculation, $\mathrm{k}$-means clustering cannot converge to the optimal solution to a large extent [43].

(2) FCM clustering

The main idea of the fuzzy c-means (FCM) clustering follows. Assume a sample set and divide it into c fuzzy groups, and then find the cluster center of each group. Comparing with k-means clustering, this clustering method integrates the essence of fuzzy theory, thereby providing more flexible clustering results. Each object is not directly assigned to a specific cluster, but a weight is assigned to each object and each cluster. If the weight is larger, the object is closer to this cluster. This method attempts to find the minimum of the following objective functions [44]:

$$
\begin{gathered}
J(A ; C)=\sum_{\mathrm{i}=1}^{k} \sum_{j=1}^{n}\left(\gamma_{i j}\right)^{\partial}\left\|A_{j}-C_{i}\right\|^{2} \\
D_{\mathrm{ij}}{ }^{2}=\left\|A_{j}-C_{i}\right\|^{2}=\left(A_{j}-C_{i}\right)^{T}\left(A_{j}-C_{i}\right)
\end{gathered}
$$

Through comparison, the difference can be found between these functions and the function of k-means clustering: the fuzzy degree of clustering is determined by the fuzzy coefficient $(\partial)$ and the member value $\left(\gamma_{i j}\right)$ together. The minimum value of the function can be obtained if [44]:

$$
\begin{gathered}
\gamma_{\mathrm{ij}}=\frac{1}{\sum_{m=1}^{k}\left(\frac{D_{i j}}{D_{m j}}\right)^{\frac{2}{\partial-1}}} ; 1 \leq i \leq k, 1 \leq j \leq n \\
C_{\mathrm{i}}=\frac{\sum_{j=1}^{n}\left(\gamma_{i j}\right)^{\partial} A_{j}}{\sum_{j=1}^{n}\left(\gamma_{i j}\right)^{\partial}} ; 1 \leq i \leq k
\end{gathered}
$$

There are three stages in the FCM clustering algorithm:

(a) Determine cluster centers according to Equations (5) and (6).

(b) Calculate the distance by Equation (4).

(c) Update the objective function according to Equation (3).

The FCM clustering has better performance than the k-means clustering, but some limitations remain. For example, the determination of the initial cluster center and member values have a great impact on the clustering results [45], which may lead to the limitation of FCM clustering at local minimum values. 
GMM is an abbreviation for Gaussian mixture model (or mixed Gaussian model). According to many phenomena in nature, Gaussian (normal) distribution is followed; nevertheless, the reasons for affecting a distribution are multiple, and each influence factor may determine one. A single effect is a Gaussian distribution; a combination of multiple effects is a multiple Gaussian distribution.

Therefore, the Gaussian mixture model can also be understood as a large model with K single models. The Gaussian distribution is generally combined with the EM algorithm as its likelihood estimation algorithm. The probability model GMM can be expressed as [46]:

$$
\begin{gathered}
\mathrm{p}(x)=\sum_{k=1}^{K} w_{k} g\left(A \mid \mu_{k}, \sum_{k}\right) \\
\mathrm{g}\left(A \mid \mu_{k}, \sum_{k}\right)=\frac{1}{\sqrt{(2 \pi)^{k}\left|\sum_{k}\right|}} \exp \left(\frac{-\frac{1}{2}\left(A-\mu_{k}\right)^{T}}{\sum_{k}\left(A-\mu_{k}\right)}\right) \\
\sum_{k=1}^{K} w_{k}=1
\end{gathered}
$$

where $w_{k}$ is the mixed weight function, $A$ are the data, and the mean vector $\mu_{k}$ and the covariance matrix $\sum_{k}$ are represented by a Gaussian density function. There are three steps in the GMM clustering algorithm [46]:

(a) First, the algorithm estimates two quantities: the mean vector and the covariance matrix. It then calculates all the data and all the blending weight functions.

(b) New parameters are calculated using membership and data. If $N_{k}=\sum_{w i k}$, the new blending weight can be expressed as:

$$
\mathrm{w}_{k}^{\text {new }}=\frac{N_{k}}{N} ; 1 \leq k \leq K
$$

The new mean vector and covariance matrix can be expressed as:

$$
\begin{gathered}
\mu_{\mathrm{k}}^{\text {new }}=\left(\frac{1}{N_{k}}\right) \sum_{i=1}^{n} w_{i k} \cdot A_{i} ; 1 \leq k \leq K \\
\sum_{k}^{n e w}=\left(\frac{1}{N_{k}}\right) \sum_{i=1}^{n} w_{i k} \cdot\left(A_{i}-\mu_{k}^{n e w w}\right)\left(A_{i}-\mu_{k}^{n e w}\right)^{T}
\end{gathered}
$$

(c) Repeat the above two steps to meet the stopping criteria.

(4) SOM clustering

The self-organizing mapping (SOM) neural network is a self-organizing and competitive network, and it is also a type of unsupervised learning model. SOM is unique in that it adopts a competitive learning approach to optimize the network. The weight vector of the "winning neuron" of the output layer and its neighboring neurons are calculated according to the following Equation [47]:

$$
\begin{gathered}
W_{v}(t+1)=W_{v}(s)+\theta(u, v, t) \cdot\left(A_{i}-W_{v}(t)\right) \\
\theta(u, v, t)=\exp \left(\frac{\left\|r_{u}-r_{v}\right\|^{2}}{2 \sigma^{2}(t)}\right)
\end{gathered}
$$

where $u$ represents the evaluation parameter of the neurons of $A_{i}, t$ represents the time, $\theta(u, v, t)$ represents the neighborhood function, $r_{u}$ and $r_{v}$ represent locations of neurons, $u$ and $v$, and $\sigma(t)$ are used to describe the width of the function $\theta(u, v, t)$. After this calculation, the configuration of the data can be obtained through the SOM clustering lattice, so as to identify and classify the internal data. 
(5) Hierarchical model clustering

The hierarchical clustering method refers to the hierarchical decomposition of the data set until a certain condition is met. The traditional hierarchical clustering algorithm mainly has two parts: agglomerative and divisive hierarchical clustering [48].

(a) Agglomerative hierarchical clustering

A bottom-up method which starts by determining each object as a single cluster, and these clusters are gradually merged according to certain criteria (the similarity measurement between the two clusters), and the clustering process repeats until all objects meet the number of clusters.

(b) Divisive hierarchical clustering

This part uses a strategy that is contrary to agglomerative hierarchical clustering: top-down, which first puts all objects into a cluster and then subdivides them into smaller clusters according to a certain metric until the distance between the two nearest clusters exceeds a certain threshold or reaches the number of clusters.

Although hierarchical clustering is relatively simple, it often encounters the problem of selecting merge points or split points. This choice is important, otherwise the process of merging or splitting will be irreversible, which means the processing completed cannot be undone, and the objects cannot be exchanged between clusters. If the decision to merge or split is not appropriate, a low quality clustering result may result. Moreover, hierarchical clustering algorithms do not have good scalability, and a large number of objects and clusters need to be examined and evaluated before deciding to merge or split.

\subsection{Introduction to Density Peak Clustering Method}

In this section, a new clustering method is applied to analyze AE data. The density peak clustering method is an improved algorithm. For the original algorithm, the determination of cluster centers can only be manually selected [49]. The improved density peak clustering algorithm can achieve automatic clustering. The specific flow chart is shown in Figure 3 . The following describes the specific steps of the density peak clustering method:

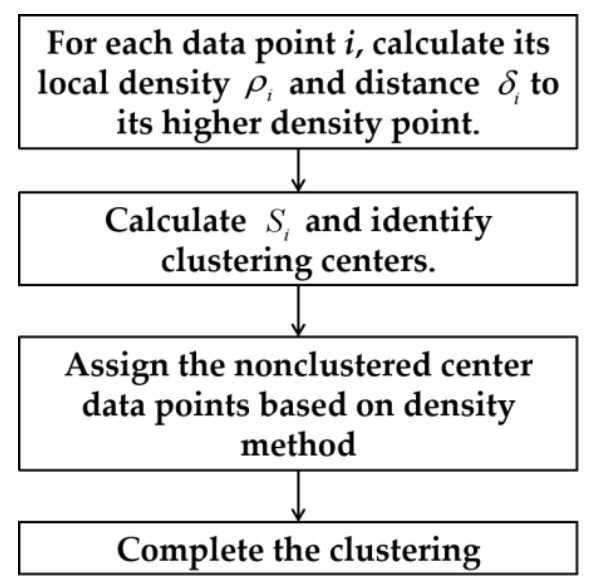

Figure 3. Flow chart of density peak clustering.

First, the density of data points is calculated. The density of data point $i$ is calculated as:

$$
\rho_{i}=\sum_{j} \chi\left(d_{i j}-d_{c}\right)
$$

where $d_{c}$ is the cutoff distance, and then calculate the distance $\delta$ from each data point to the data point with greater local density and the closest distance, as follows:

$$
\delta_{i}=\min _{j: \rho_{j} \geq \rho_{i}}\left(d_{i j}\right)
$$


Second, for purpose of automatically identifying the cluster center, the density peak $S$ is used to measure the weight of each point as a candidate for the cluster center, as follows:

$$
S_{i}=\rho_{i} \times \delta_{i}
$$

Finally, there are several large values of $S_{i}$, and data points are divided into several clusters based on the density method.

\subsection{Introduction to Artificial Neural Network Method}

An artificial neural network is a program that can effectively extract nonlinear data characteristics. It can provide computerized positioning and identify differential faults without requiring a large amount of understanding of sample behavior. It mainly has three parts: input, output, and hidden layer (Figure 4); the three layers are connected to form a network.

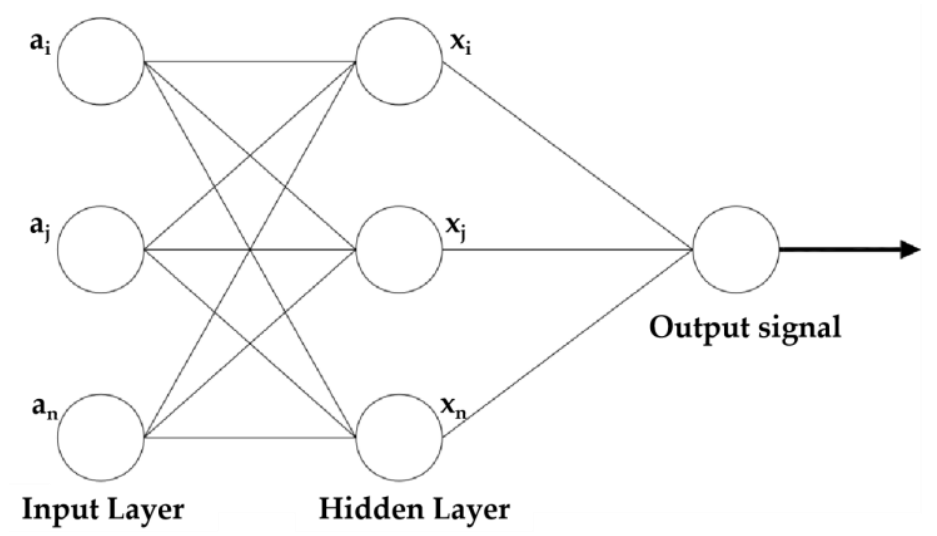

Figure 4. Artificial neural network structure.

Artificial neural networks typically use the gradient descent method [50-52] to perform error minimization efforts. The random weight is calculated by the given network connection method and the output initial value. The network performance can be improved through continuous loop iterations, and finally determine the most reliable system structure and the appropriate number of cycles [53].

\section{Results and Discussion}

In this section, the characteristic parameters of the AE signals collected from the crumb rubber concrete specimens in the four-point bending test were analyzed, mainly involving the following 10 parameters: rise time, count, energy, duration, amplitude, RMS, ASL, signal strength, center frequency, and peak frequency. The rise time and duration refer to the time interval between when the AE signal crosses the threshold and the maximum amplitude, and when the AE signal crosses the threshold and drops to the threshold, respectively. Count refers to the number of oscillations of the AE signal crossing the threshold, and energy refers to the area enclosed by the coordinates below the waveform. Additionally, center frequency and peak frequency refer to the information in the spectrum obtained from the FFT of the AE signal.

\subsection{Damage Pattern Recognition}

\subsubsection{Clustering Results of Common Clustering Methods}

The five common clustering methods described above have one aspect in common: they all need to be classified first and then the optimal number of clusters determined. Therefore, it is necessary to find the cluster number before using the five common clustering methods to cluster the crumb rubber concrete acoustic emission signals. To solve this problem, four evaluation indexes, Davies-Bouldin, Tou, Silhouette [54], and Dunn, were used in this paper. 
When using the five common clustering methods and four clustering evaluation indexes in the clustering analysis, a total of six acoustic emission parameters, including rise time, count, energy, duration, amplitude, and peak frequency, were used for analysis $[55,56]$. The clustering evaluation index results of these five commonly used clustering methods can be seen in Figure 5. According to the description of the four clustering evaluation indicators in this section, the smaller the Davies-Bouldin (DB) index, the better the classification effect. The Dunn (D) index, the Silhouette index, and the Tou index are numerical values indicating classification; the higher their value, the better the classification effect. According to Figure 5, the optimal clustering number corresponding to these five clustering methods is three.

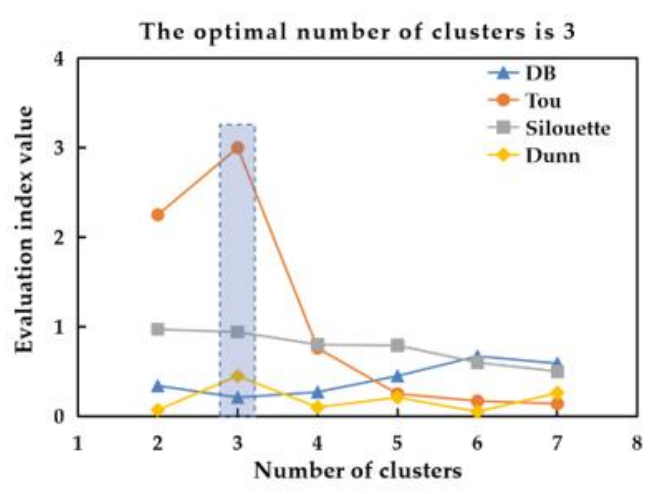

(a)

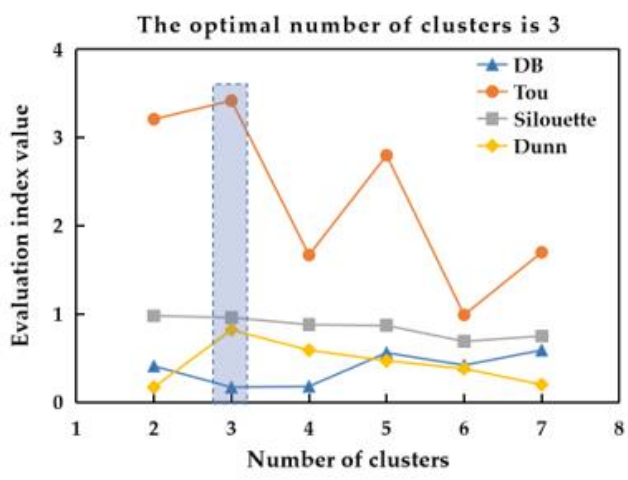

(c)

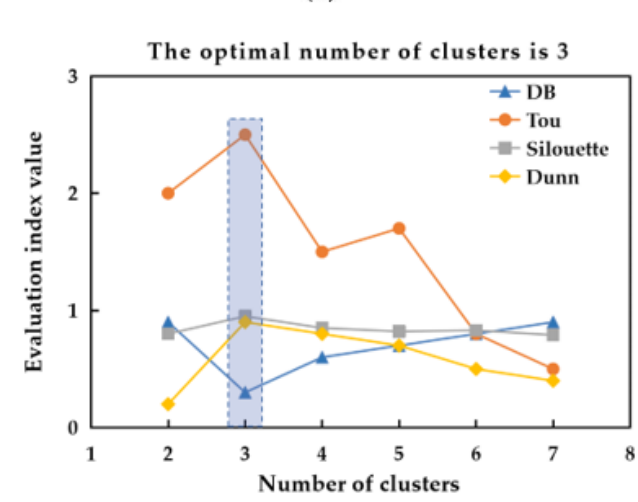

(e)

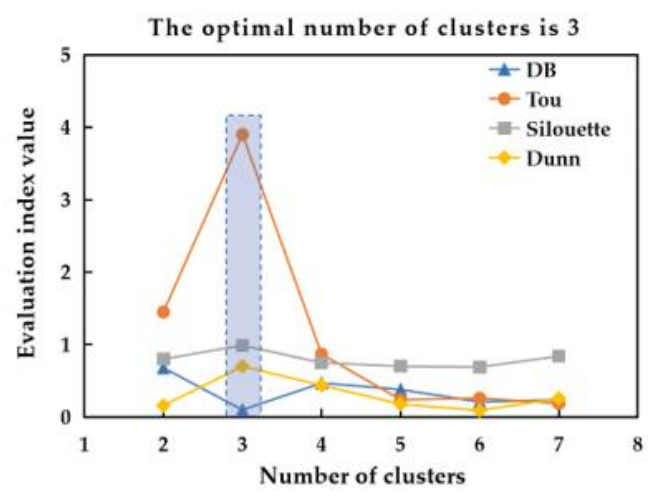

(b)

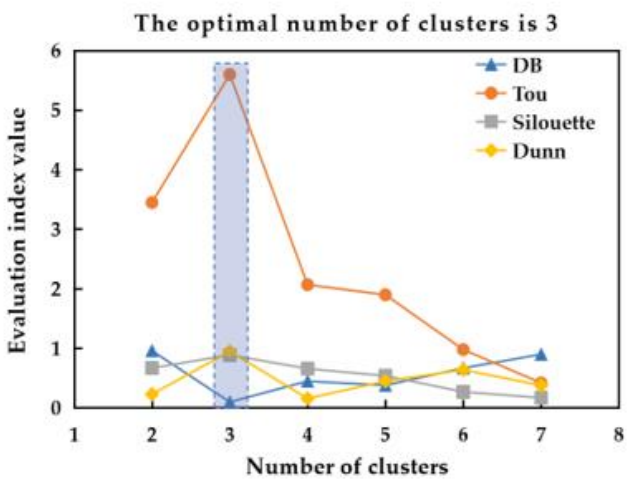

(d) 
In addition, according to the clustering results of the five commonly used clustering methods shown in Figure 6, it is found that some data points cannot be clearly distinguished, and the division of the three clusters is not particularly obvious. Therefore, it is crucial to find a better clustering method to analyze the acoustic emission data of crumb rubber concrete.

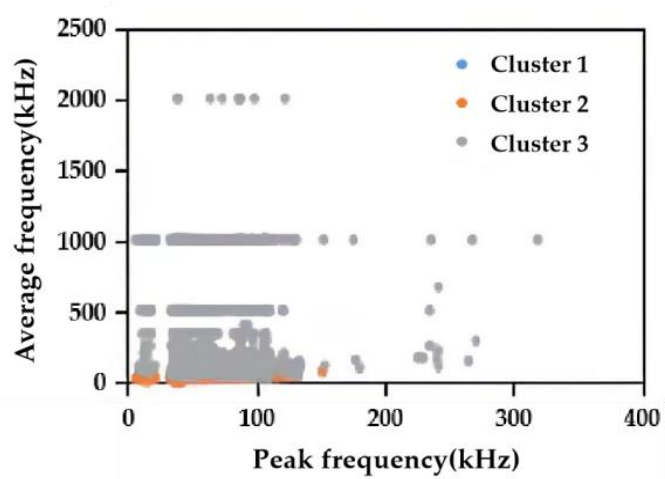

(a)

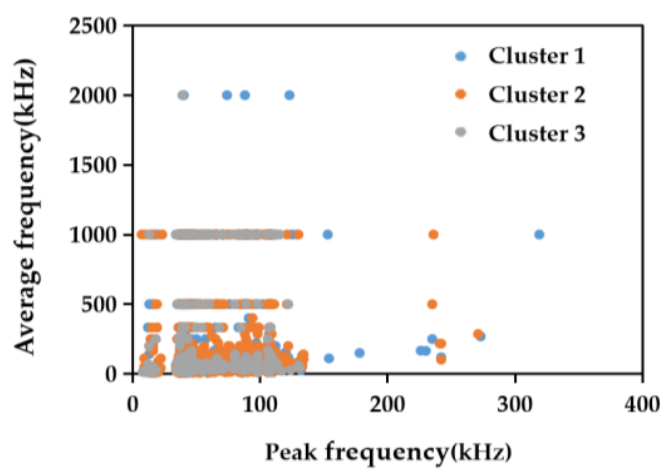

(c)

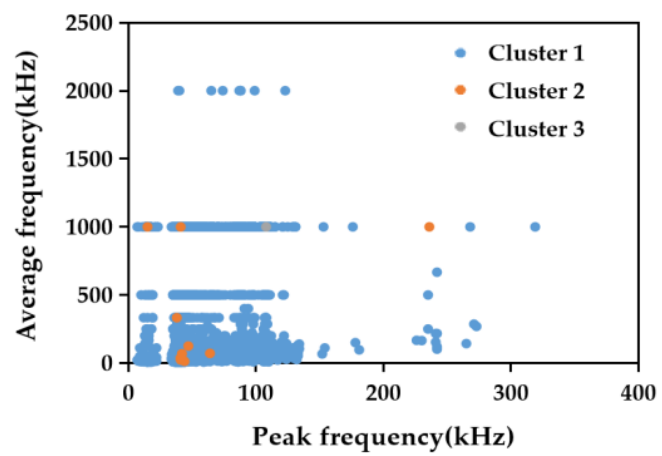

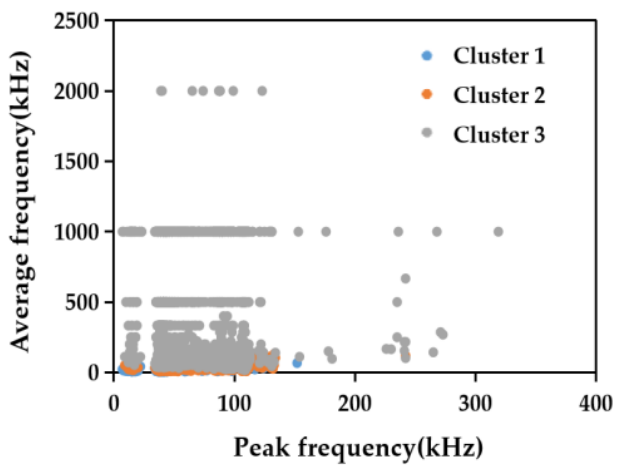

(b)

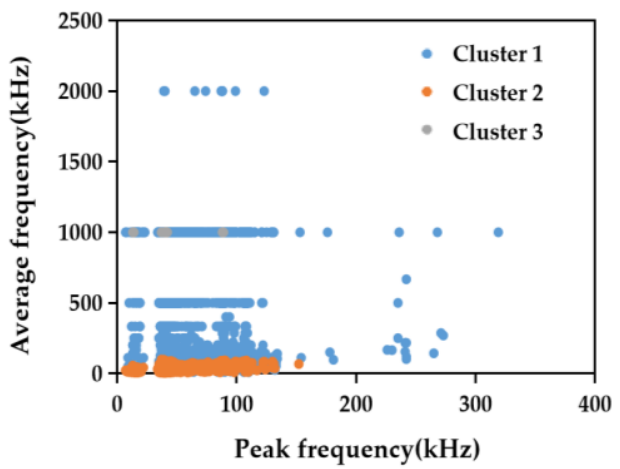

(d)

(e)

Figure 6. Clustering results of common clustering methods: (a) k-means clustering; (b) FCM clustering; (c) GMM clustering; (d) SOM clustering; (e) hierarchical clustering.

\subsubsection{Clustering Results of the Density Peak Clustering Method}

Based on the introduction of the density peak clustering method provided previously, this method was adopted to process the experimental data of crumb rubber concrete. Similarly, six acoustic emission parameters-rise time, count, energy, duration, amplitude, 
and peak frequency - were used as input data, and the peak density of each data point is shown in Figure 7. The 2210th data point, the 5176th data point and the 14,373rd data point have significantly higher density peaks than the other data points. Based on the principle of density peak clustering, these three points were used as the density center. The cluster center of the peak cluster, and all the remaining data points were classified separately.

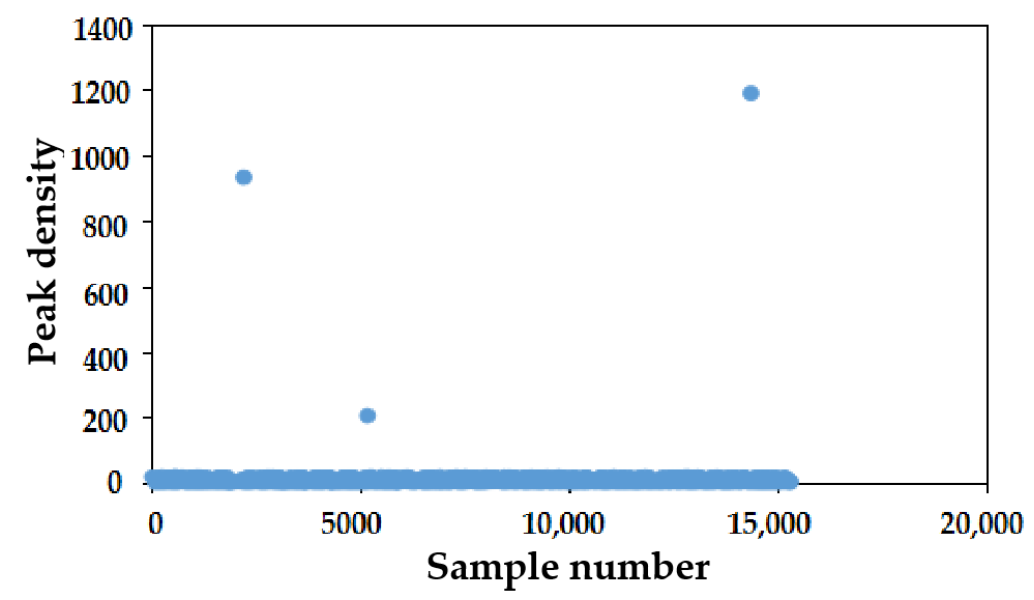

Figure 7. Peak density of sample points.

After clustering by using the density peak method, the method described in this section also uses the average frequency and peak frequency to evaluate the clustering results. Based on Figure 8, the data points are well divided into three clusters, which can be clearly distinguished, and the average frequency between different clusters can be clearly discerned. The clustering performance is obviously better than the clustering performance of the five commonly used clustering methods noted above. Therefore, the density peak clustering method is the best clustering method for analyzing the acoustic emission data of crumb rubber concrete. This method can be used to perform deeper damage pattern recognition of crumb rubber concrete.

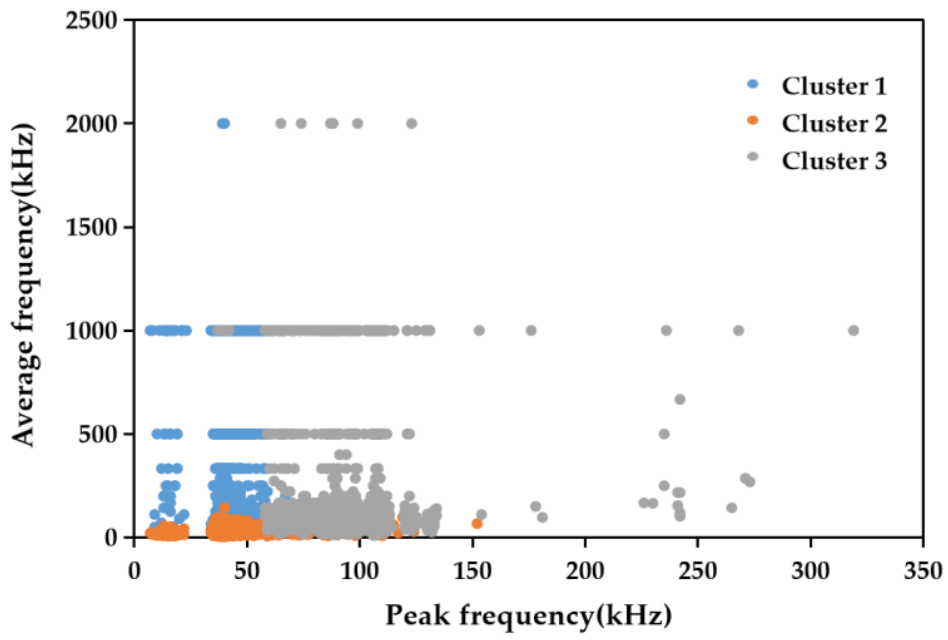

Figure 8. Density peak clustering results.

3.1.3. Damage Pattern Recognition of Crumb Rubber Concrete by the Density Peak Clustering Method

According to previous studies, it can be shown that the peak frequency of AE signals generated by the structural failure of concrete changes with the change of the concrete damage mode. Thus, various damage patterns of concrete can be identified and characterized through the peak frequency. The statistical analysis and comparison of the peak 
frequencies of different events in two kinds of concrete (ordinary concrete and crumb rubber concrete) were carried out (Figures 9 and 10). For ordinary concrete, the peak frequency distribution is mainly concentrated in one band, about $35 \sim 50 \mathrm{kHz}$. Hence, Figure 9 shows that the peak frequency of the main frequency band corresponding to the destruction of the concrete matrix, which is about $35 \sim 50 \mathrm{kHz}$. For crumb rubber concrete, due to the incorporation of rubber, another frequency band with a peak frequency of $85 \sim 125 \mathrm{kHz}$ is added to Figure 10, which also represents another new failure mode in addition to the failure of the concrete matrix.

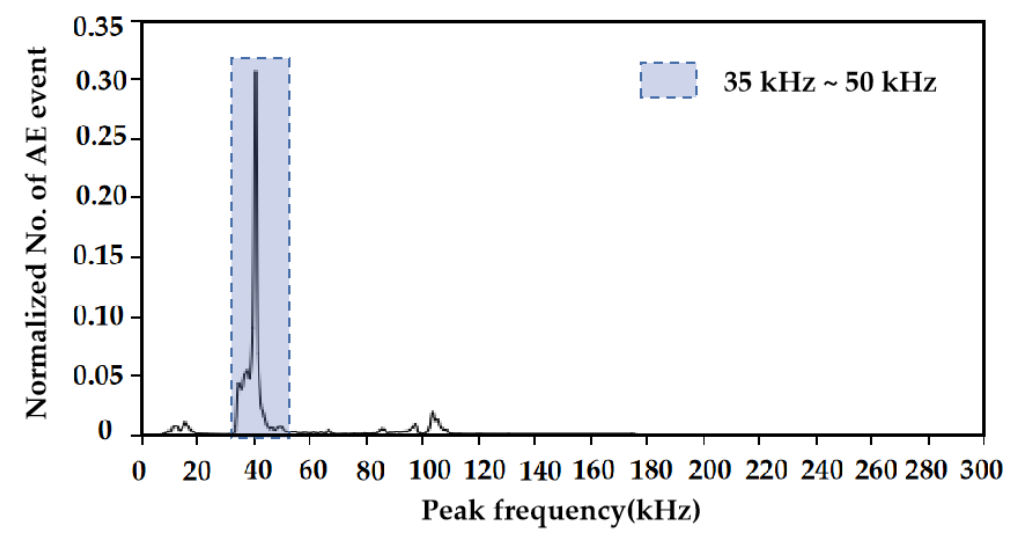

Figure 9. Peak frequency distribution of ordinary concrete.

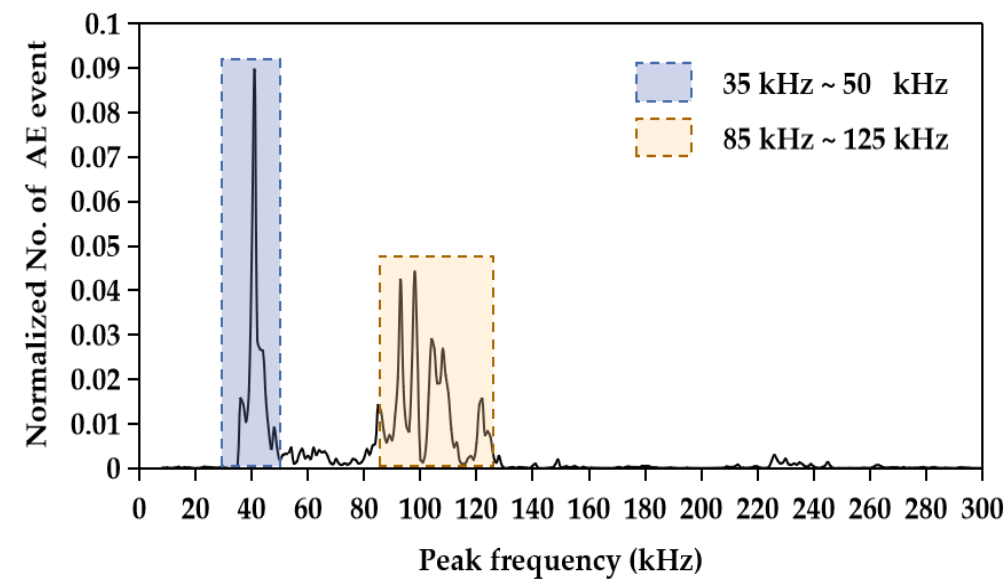

Figure 10. Peak frequency distribution of crumb rubber concrete.

Based on the results of density peak clustering, the optimal clustering number of crumb rubber concrete is three. Therefore, the acoustic emission signals of crumb rubber concrete were classified into three clusters. According to Figure 11, for the peak frequency of the crumb rubber concrete $\mathrm{AE}$ signals, the distribution range of cluster 1 is 10 to $66 \mathrm{kHz}$, and its main frequency band is 35 to $50 \mathrm{kHz}$. According to the previous analysis, the damage pattern represented by the cluster 1 signal is the cracking of the concrete matrix. The peak frequency of cluster 2 ranges from 5 to $170 \mathrm{kHz}$, of which the two main frequency bands are 35 to $50 \mathrm{kHz}$ and 85 to $125 \mathrm{kHz}$, respectively, which shows that the signal of cluster 2 represents two failure modes: concrete matrix cracking accompanied by rubber particle fracture. The peak frequency distribution of cluster 3 ranges from 20 to $150 \mathrm{kHz}$, and it has only a main frequency band of 85 to $125 \mathrm{kHz}$, indicating that the signal of cluster 3 represents a new damage mode after rubber incorporation. 


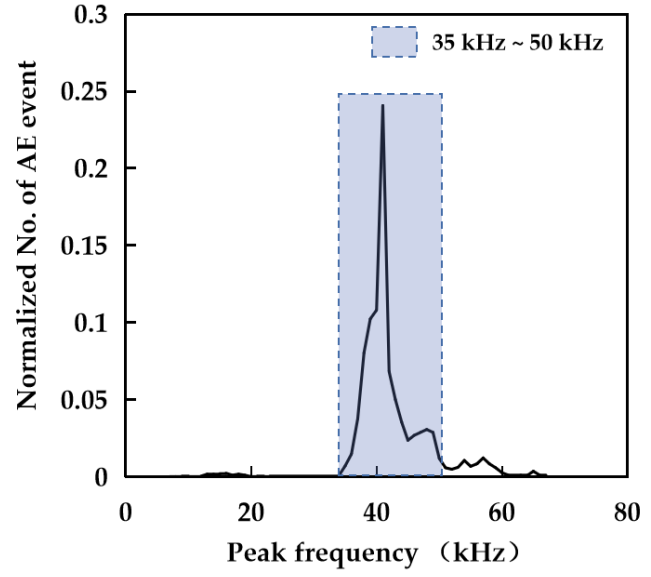

(a)

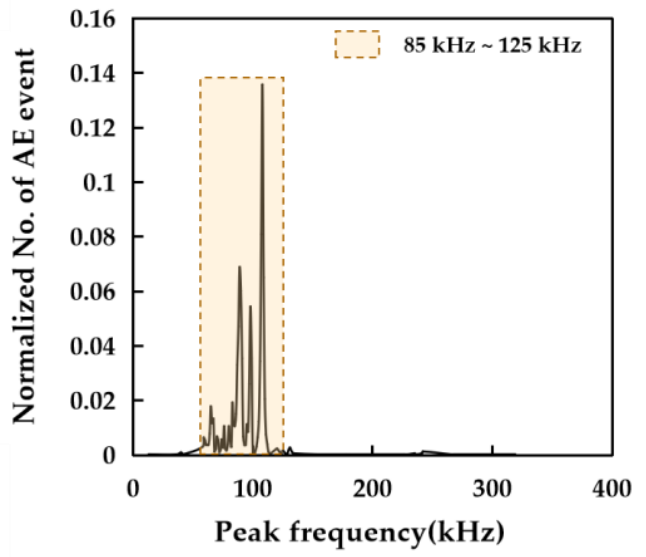

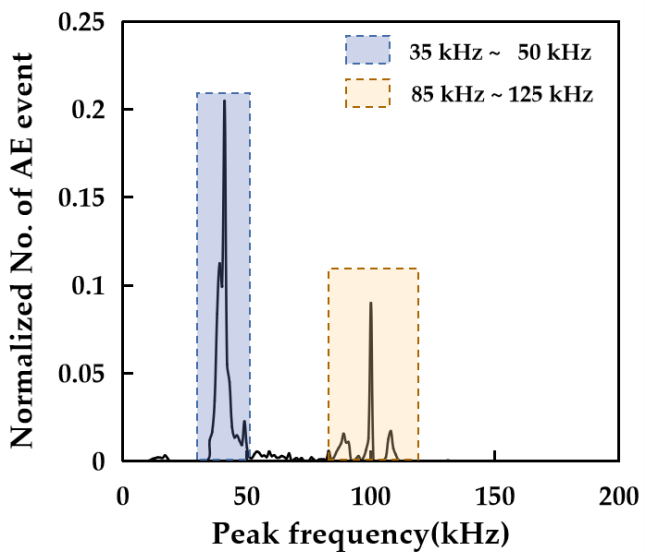

(b)

(c)

Figure 11. Peak frequency distribution of three clusters: (a) cluster 1 ; (b) cluster 2; (c) cluster 3.

In addition, the cumulative energy of $\mathrm{AE}$ parameters and the length of the propagating cracks generated when concrete is destroyed have also been studied, and scholars have proved that there is a certain correlation between the two. According to Figure 12, the cumulative energy of the signal of cluster 2 over time is much higher than that of the signals of cluster 1 and cluster 3 , which indicates that the signal of cluster 2 corresponds to the larger damage inside the concrete matrix, also proving that the signal of cluster 2 includes not only the cracking of the concrete matrix, but also the new failure mode caused by rubber. At the same time, it should be noted that for concrete structures, the acoustic waves generated when the internal fractures are continuously attenuated during the propagation process, and considering that the distance between each acoustic emission sensor and the damage location is different, there is a certain error between the peak frequency received by sensors and the peak frequency at the original location of the concrete damage, which cannot be ignored. Thus, for different failure modes, it is crucial to find another method to more finely determine their corresponding peak frequencies. 


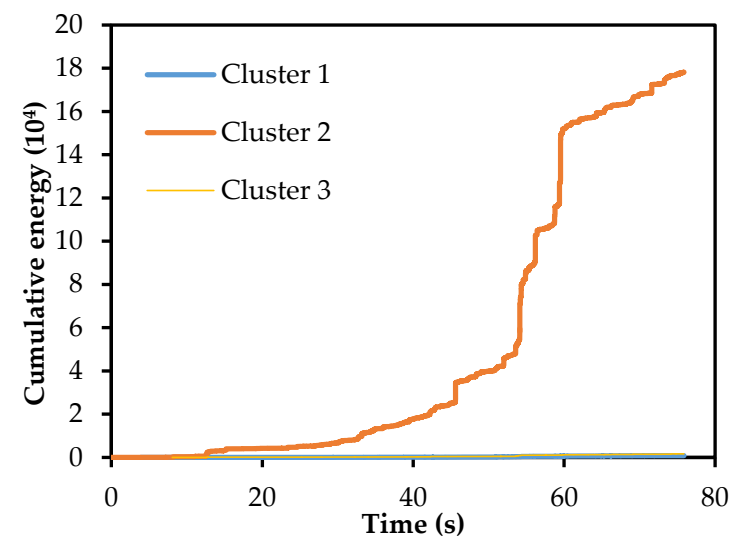

Figure 12. Cumulative energy of three clusters.

Fast Fourier transform (FFT) is a calculation method that transforms the time domain into the frequency domain. Due to its high efficiency and speed, this method is commonly used to process acoustic emission waveform signals. For crumb rubber concrete, the peak frequencies of the cluster 1 and the cluster 3 signals have two identical main peaks: 40 and $100 \mathrm{kHz}$. Among them, the peak frequency $40 \mathrm{kHz}$ of cluster 1 corresponds to a larger amplitude, and the peak frequency $100 \mathrm{kHz}$ of cluster 3 corresponds to a larger amplitude (Figure 13). This indicates that the failure mode reflected by the cluster 1 signal and the cluster 3 signal corresponds to these two main peaks, which are mentioned above: the damage of the concrete matrix and the new failure mode caused by the incorporation of rubber. Meanwhile, the cluster 1 signal and cluster 3 signal are based on the failure mode of the concrete matrix $(40 \mathrm{kHz})$ and the new failure mode $(100 \mathrm{kHz})$ caused by rubber incorporation, respectively. Therefore, for different damage modes, the FFT method can be used to make their corresponding peak frequencies more accurate. Through FFT calculation, it is found that for rubber concrete, the cluster 1 signal is mainly the destruction of the concrete matrix, which also includes the new failure mode caused by rubber fracture. Meanwhile, the cluster 3 signal is mainly caused by the rubber fracture but also includes the damage of the concrete matrix.

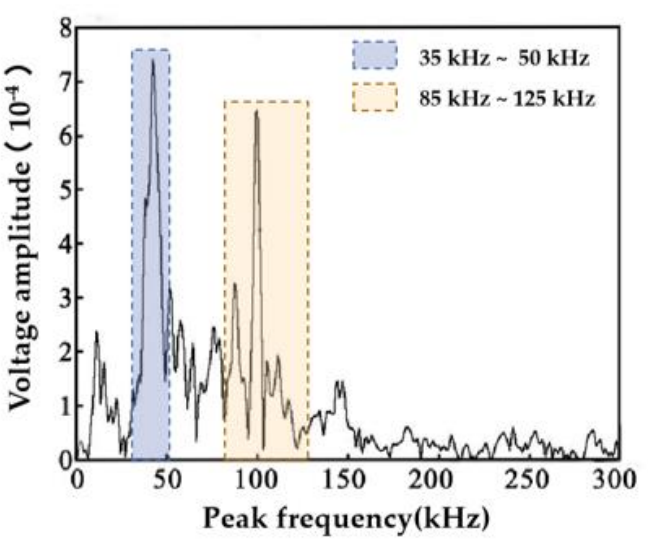

(a)

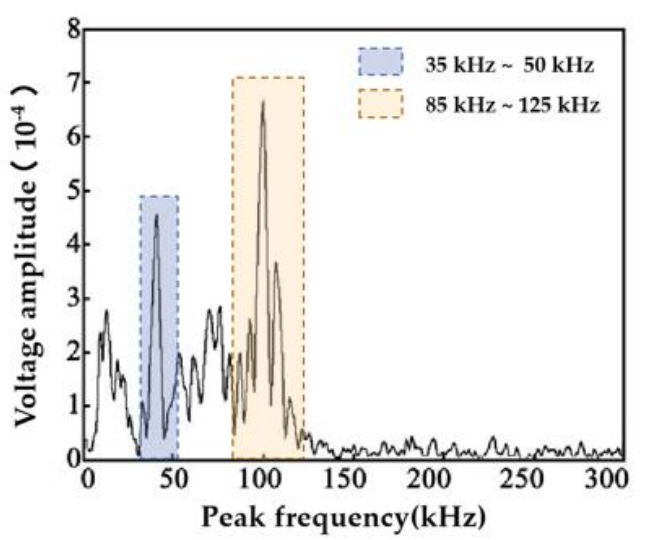

(b)

Figure 13. FFT spectrum characteristic maps: (a) cluster 1; (b) cluster 3.

According to Table 3, the average value of the rise time, count, energy, duration, and amplitude of the cluster 3 signal (mainly caused by a new failure mode caused by rubber) is higher than the cluster 1 signal (mainly caused by the destruction of the concrete matrix), respectively. Thus, the intensity of the cluster 3 signal is slightly greater than the cluster 1 signal. 
Table 3. Average AE parameters of cluster 1 and cluster 3.

\begin{tabular}{lccccccc}
\hline $\begin{array}{c}\text { Name of } \\
\text { Cluster }\end{array}$ & $\begin{array}{c}\text { Rise Time } \\
(\mathbf{m s})\end{array}$ & Count & $\begin{array}{c}\text { Energy } \\
(\mathbf{m s} \times \boldsymbol{\mu v})\end{array}$ & $\begin{array}{c}\text { Duration } \\
(\mathbf{m s})\end{array}$ & Amplitude & $\begin{array}{c}\text { Average } \\
\text { Frequency } \\
(\mathbf{k H z})\end{array}$ & RMS $^{\mathbf{1}}$ \\
\hline Cluster 1 & 6.98 & 1.46 & 0.26 & 16.29 & 41.43 & 42.25 & 398.91 \\
Cluster 3 & 9.57 & 2.50 & 0.57 & 31.11 & 42.65 & 95.81 & 38.18 \\
\hline
\end{tabular}

${ }^{1}$ RMS: root mean square.

The average frequency (AF) refers to the ratio of the ringing counts to the duration time. Many scholars have found that the average frequency of acoustic emission signals corresponding to different damage modes is different. For example, the average frequency of acoustic emission signals produced by tensile damage is higher, while the average frequency of acoustic emission signals produced by shear damage is lower [52]. The calculation Equation of the AF follows:

$$
\mathrm{AF}=\mathrm{AE} \text { ringdown counts } / \text { the duration time }
$$

According to Table 3 , the average frequency of cluster 1 and 3 signals are quite different. By comparing the average frequencies of these two clusters of signals, the different damage modes in crumb rubber concrete are further characterized. Figure 14 shows that the average frequency of cluster 1 (mainly caused by the destruction of the concrete matrix) is $1000 \mathrm{kHz}$, and the cluster 3 signal caused by the new failure mode has an average frequency band of 0 to $100 \mathrm{kHz}$. Hence, the main failure mode of the cluster 1 signal is the tensile failure mode, and the main failure mode of the cluster 3 signal is the shear failure mode.

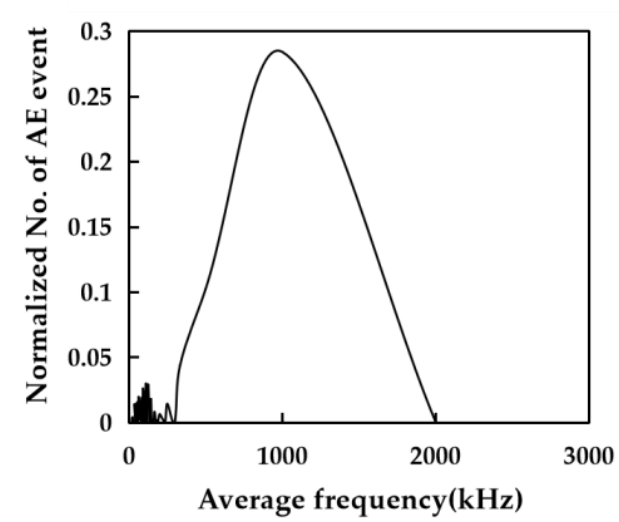

(a)

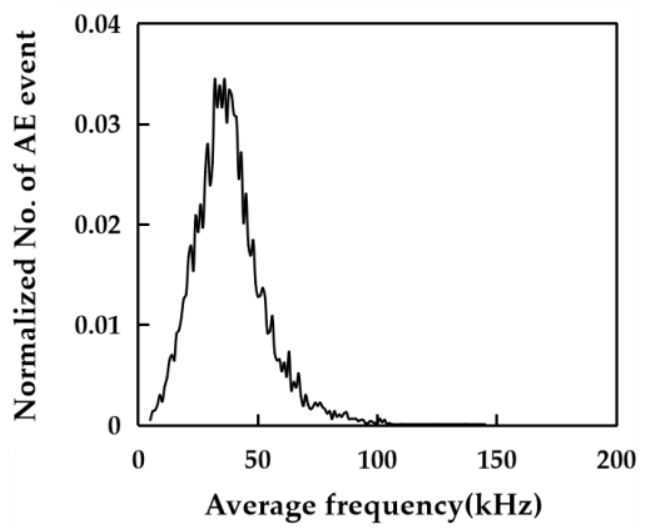

(b)

Figure 14. Average frequency distribution: (a) cluster 1; (b) cluster 3.

\subsection{Prediction of Ultimate Damage Load}

In the previous section, the damage patterns of crumb rubber concrete were successfully identified using the $\mathrm{AE}$ technique combined with the selected optimal clustering method. At the same time, it is important to find a simple and effective method for predicting the ultimate damage load for crumb rubber concrete in order to ensure the safety of this material for a wide range of applications in practical engineering. On the other hand, the combination of damage pattern recognition and ultimate load prediction is more beneficial to characterize the damage mechanism of crumb rubber concrete. Therefore, in this section, a prediction model of ultimate load was proposed from the function of the AE technique with prediction of crack propagation combined with the artificial neural network.

\subsubsection{Prediction of Artificial Neural Network of Acoustic Emission Single-Parameter Data}

In this four-point bending test, nine crumb rubber concrete specimens were used: three specimens in which the rubber content was $5 \%, 10 \%$, and $15 \%$ for each. The specific 
dimensions of the experimental specimens can be seen in the experimental part. In predicting the damage ultimate load of crumb rubber concrete using the artificial neural network, the AE signals and load data of one specimen from each of the three sets of specimens with different rubber contents were extracted as the prediction set, and the AE signals and load data of the other two specimens from the same set were used as the training set to predict the damage ultimate load of the specimens. This operation was repeated three times with different specimens, and the predicted and true values of the three sets of results were averaged and analyzed for errors.

In this section, 10 acoustic emission parameters-rise time (1), count (2), energy (3), duration (4), amplitude (5), RMS (6), ASL (7), signal strength (8), center frequency (9), and peak frequency (10)-predict the damage ultimate load of three different crumb rubber concretes, and compare the prediction results with their true values to calculate the prediction error. The Matlab 10 Neural Network Toolbox was used to train the networks. The Levenberge-Marquardt algorithm was used for back propagation during training. At the same time, the learning rate was set to 0.9 in the calculation process.

In the process of obtaining the prediction results shown in Tables 4-13, the input data are a matrix composed of the single acoustic emission parameter column vectors of the six crumb rubber concrete specimens, and the hidden layer is composed of nine neurons, and the output end is the predicted value of the ultimate load of the crumb rubber concrete. The prediction result of the artificial neural network with a single parameter of rise time follows: when the number of iterations reaches 80 , the average error (MSE) reaches the minimum value (Figure 15a); that is, the optimal number of training iterations is 80 times. At the same time, the best iteration numbers of the other nine acoustic emission parameters can also be determined from Figure 15b-j. Table 4 shows that the maximum prediction error of the specimens with three different rubber contents is $-2.39 \%$. It is concluded that the single-parameter neural network with rise time predicts that the damage ultimate load error of crumb rubber concrete is small, and the results using different acoustic emission parameters is different from what is shown in Tables 4-13.

Table 4. Rise time (1) single-parameter neural network prediction results.

\begin{tabular}{cccc}
\hline Rubber Content & Actual Value (kN) & Predictive Value (kN) & Prediction Error \\
\hline $5 \%$ & 16.24 & 15.85 & $-2.39 \%$ \\
$10 \%$ & 15.27 & 15.48 & $-1.36 \%$ \\
$15 \%$ & 11.32 & 11.50 & $1.56 \%$ \\
\hline
\end{tabular}

Table 5. Ringing count (2) single-parameter neural network prediction results.

\begin{tabular}{cccc}
\hline Rubber Content & Actual Value (kN) & Predictive Value (kN) & Prediction Error \\
\hline $5 \%$ & 16.24 & 14.09 & $-13.23 \%$ \\
$10 \%$ & 15.27 & 14.43 & $-5.52 \%$ \\
$15 \%$ & 11.32 & 12.15 & $7.28 \%$ \\
\hline
\end{tabular}

Table 6. Energy (3) single-parameter neural network prediction results.

\begin{tabular}{cccc}
\hline Rubber Content & Actual Value (kN) & Predictive Value (kN) & Prediction Error \\
\hline $5 \%$ & 16.24 & 17.84 & $9.86 \%$ \\
$10 \%$ & 15.27 & 15.03 & $-1.56 \%$ \\
$15 \%$ & 11.32 & 12.08 & $6.71 \%$ \\
\hline
\end{tabular}


Table 7. Duration (4) single-parameter neural network prediction results.

\begin{tabular}{cccc}
\hline Rubber Content & Actual Value (kN) & Predictive Value (kN) & Prediction Error \\
\hline $5 \%$ & 16.24 & 17.15 & $5.61 \%$ \\
$10 \%$ & 15.27 & 14.53 & $-4.87 \%$ \\
$15 \%$ & 11.32 & 12.34 & $9.02 \%$ \\
\hline
\end{tabular}

Table 8. Amplitude (5) single-parameter neural network prediction results.

\begin{tabular}{cccc}
\hline Rubber Content & Actual Value (kN) & Predictive Value (kN) & Prediction Error \\
\hline $5 \%$ & 16.24 & 16.57 & $2.07 \%$ \\
$10 \%$ & 15.27 & 14.90 & $-2.45 \%$ \\
$15 \%$ & 11.32 & 10.97 & $-3.12 \%$ \\
\hline
\end{tabular}

Table 9. RMS (6) single-parameter neural network prediction results.

\begin{tabular}{cccc}
\hline Rubber Content & Actual Value (kN) & Predictive Value (kN) & Prediction Error \\
\hline $5 \%$ & 16.24 & 14.82 & $-8.76 \%$ \\
$10 \%$ & 15.27 & 15.77 & $3.27 \%$ \\
$15 \%$ & 11.32 & 12.83 & $13.26 \%$ \\
\hline
\end{tabular}

Table 10. ASL (7) single-parameter neural network prediction results.

\begin{tabular}{cccc}
\hline Rubber Content & Actual Value (kN) & Predictive Value (kN) & Prediction Error \\
\hline $5 \%$ & 16.24 & 17.42 & $7.26 \%$ \\
$10 \%$ & 15.27 & 16.52 & $8.15 \%$ \\
$15 \%$ & 11.32 & 12.48 & $10.25 \%$ \\
\hline
\end{tabular}

Table 11. Signal strength (8) single-parameter neural network prediction results.

\begin{tabular}{cccc}
\hline Rubber Content & Actual Value (kN) & Predictive Value (kN) & Prediction Error \\
\hline $5 \%$ & 16.24 & 16.44 & $-13.23 \%$ \\
$10 \%$ & 15.27 & 14.31 & $-5.52 \%$ \\
$15 \%$ & 11.32 & 12.64 & $7.28 \%$ \\
\hline
\end{tabular}

Table 12. Center frequency (9) single-parameter neural network prediction results.

\begin{tabular}{cccc}
\hline Rubber Content & Actual Value (kN) & Predictive Value (kN) & Prediction Error \\
\hline $5 \%$ & 16.24 & 16.48 & $1.46 \%$ \\
$10 \%$ & 15.27 & 14.39 & $-5.78 \%$ \\
$15 \%$ & 11.32 & 12.12 & $7.04 \%$ \\
\hline
\end{tabular}

Table 13. Peak frequency (10) single-parameter neural network prediction results.

\begin{tabular}{cccc}
\hline Rubber Content & Actual Value (kN) & Predictive Value (kN) & Prediction Error \\
\hline $5 \%$ & 16.24 & 16.57 & $2.04 \%$ \\
$10 \%$ & 15.27 & 15.05 & $-1.47 \%$ \\
$15 \%$ & 11.32 & 11.89 & $5.00 \%$ \\
\hline
\end{tabular}


(a)

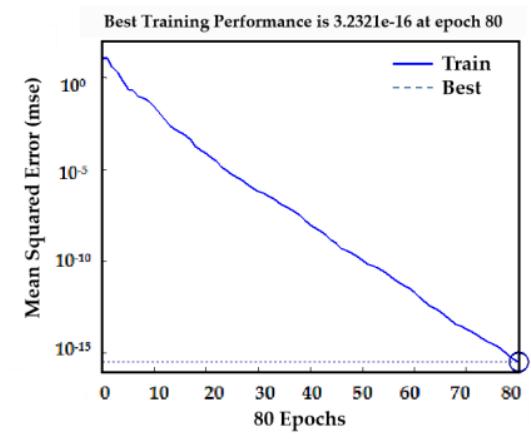

(c)

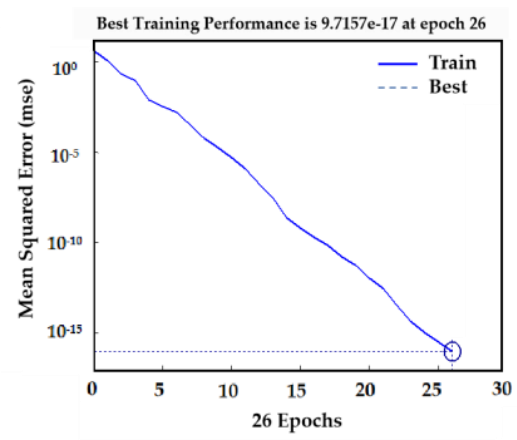

(e)

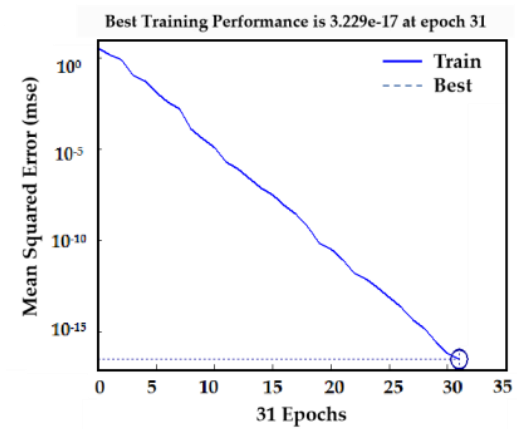

(g)

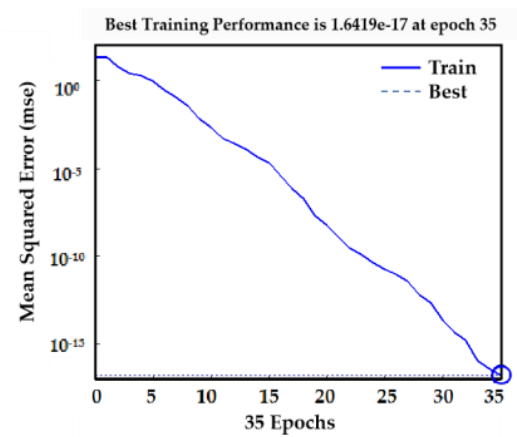

(i)

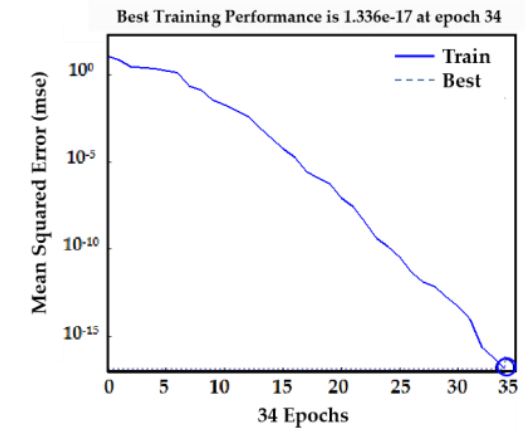

(b)

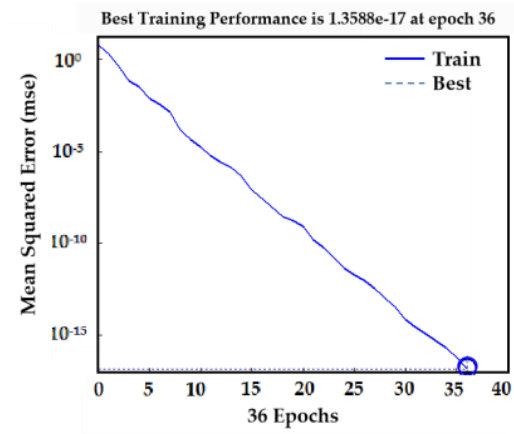

(d)

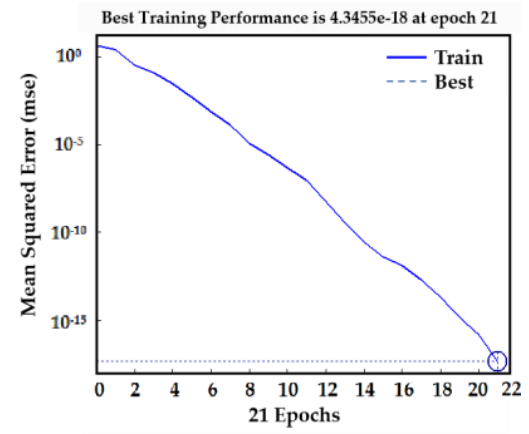

(f)

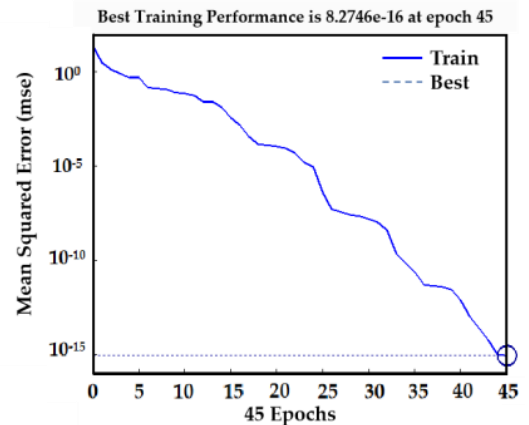

(h)

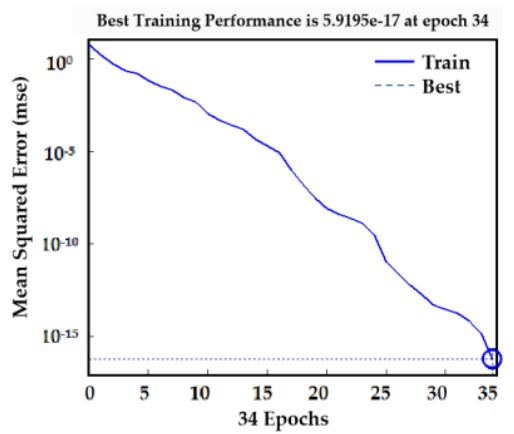

(j)

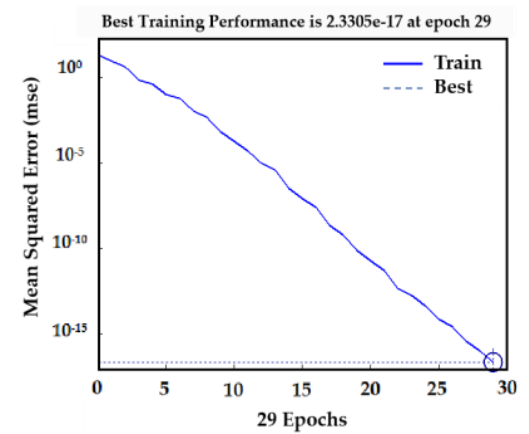

Figure 15. Ten single-parameter neural network training performance results: (a) rise time; (b) count; (c) energy; (d) duration; (e) amplitude; (f) RMS; (g) ASL; (h) signal strength; (i) center frequency; (j) peak frequency. 
Figure 16 shows the absolute values of the prediction errors of the $10 \mathrm{AE}$ singleparameter neural networks. The prediction errors of the two single-parameter neural networks with rise time (1) and amplitude (5) are relatively small. The predictions with center frequency (9) and peak frequency (10) are moderate, all within $8 \%$. The remaining parameters of the neural network prediction results are poor. Therefore, rise time is the most suitable acoustic emission parameter for single-parameter neural network prediction of crumb rubber concrete failure load.

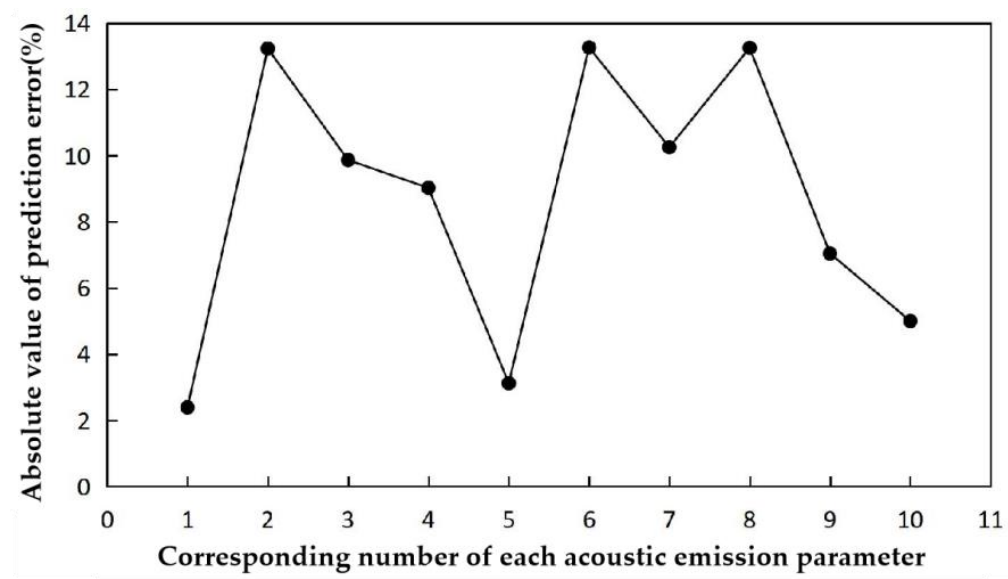

Figure 16. Prediction error of each single-parameter neural network.

\subsubsection{Prediction of Artificial Neural Network of Acoustic Emission Two-Parameter Data}

In this section, using the rise time (1) and amplitude (5) acoustic emission parameters, the damage ultimate loads of three different crumb rubber concretes were predicted by the acoustic emission two-parameter data artificial neural network. The prediction result was calculated by comparing the predicted result with its true value. The training tools and algorithms are the same as the prediction using AE single parameter.

In the process of deriving the prediction results shown in Table 14, the input data consist of a two-parameter matrix composed of the rise time and amplitude column vectors of six specimens, and the hidden layer consisting of nine nerves. The composition of the element is the predicted value of the ultimate load of the crumb rubber concrete. The artificial neural network prediction result with rise time and amplitude double parameters provides an optimal number of 39 training iterations (Figure 17). At the same time, the maximum prediction error of the specimens with three different rubber contents is $2.11 \%$, shown in Table 14. It can be concluded that the rise-time-amplitude two-parameter neural network is useful to predict the damage ultimate load of crumb rubber concrete.

Table 14. Rise-time-amplitude (RA) two-parameter neural network prediction results.

\begin{tabular}{cccc}
\hline Rubber Content & Actual Value (kN) & Predictive Value (kN) & Prediction Error \\
\hline $5 \%$ & 16.24 & 16.39 & $0.91 \%$ \\
$10 \%$ & 15.27 & 15.53 & $1.71 \%$ \\
$15 \%$ & 11.32 & 11.56 & $2.11 \%$ \\
\hline
\end{tabular}

After using these two acoustic emission parameters to combine the two-parameter neural network prediction of the ultimate load of crumb rubber concrete, the error of prediction with this set of two parameters is the smallest and less than the respective prediction errors of these two parameters. Thus, the rise-time-amplitude two-parameter combination is the most suitable for the two-parameter neural network to determine the acoustic emission parameters of the crumb rubber concrete failure load. Furthermore, the prediction error of all acoustic emission two-parameter neural network models is significantly smaller than that of the corresponding acoustic emission single-parameter 
neural network parameter model. Figure 17 shows the two-parameter optimal combination rise-time-amplitude (RA) neural network training performance.

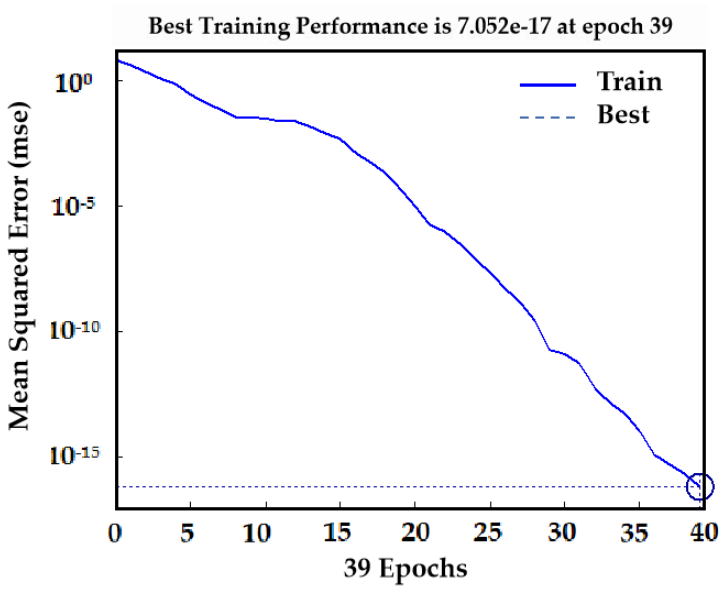

Figure 17. Two-parameter rise-time-amplitude (RA) neural network training performance.

3.2.3. Prediction of Artificial Neural Network of Acoustic Emission Multiparameter Data

In this section, five acoustic emission parameters were used together, including rise time (1), duration (4), amplitude (5), center frequency (9), and peak frequency (10) as the input data for three different rubber contents. The ultimate load of the crumb rubber concrete was predicted by the acoustic wave multiparameter data artificial neural network, and the prediction result was compared with its real value to calculate the prediction error. The training tools and algorithms are the same as the prediction using AE single parameter.

In the process of reporting the prediction results in Table 15, the input data are the rise time (1), duration (4), amplitude (5), center frequency (9), and peak frequency (10) of the six crumb rubber concrete specimens. Therefore, it is a multiparameter matrix composed of five column vectors. The hidden layer is composed of nine neurons, and the output end is the predicted value of the ultimate load. As for the prediction results of the artificial neural network using AE multiparameters, the optimal number of training iterations is 52 (Figure 18). At the same time, Table 15 shows that the maximum prediction error of the specimens with three different rubber contents is only $0.89 \%$. Therefore, the multiparameter neural network is useful to predict the ultimate load of crumb rubber concrete.

Table 15. Multiparameter neural network prediction results.

\begin{tabular}{cccc}
\hline Rubber Content & Actual Value (kN) & Predictive Value (kN) & Prediction Error \\
\hline $5 \%$ & 16.24 & 16.35 & $0.71 \%$ \\
$10 \%$ & 15.27 & 15.20 & $-0.47 \%$ \\
$15 \%$ & 11.32 & 11.42 & $0.89 \%$ \\
\hline
\end{tabular}

Ten acoustic emission single parameters, rise-time-amplitude (RA) two-parameter and multiparameter neural network prediction error absolute values are also shown in Figure 19, which can be summarized by comparison: the acoustic emission multiparameter neural network prediction results are the most accurate and the prediction error is no more than $1 \%$. The rise-time-amplitude (RA) two-parameter neural network prediction results are also small. 


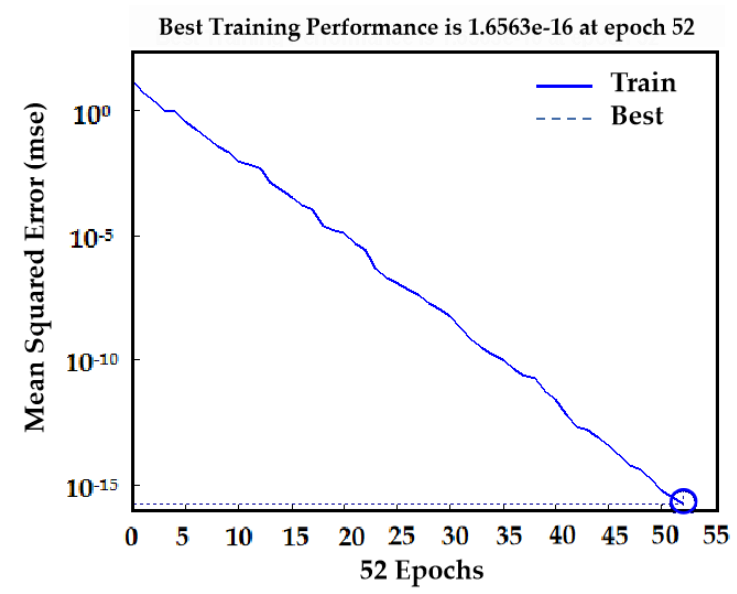

Figure 18. Multiparameter neural network training performance.

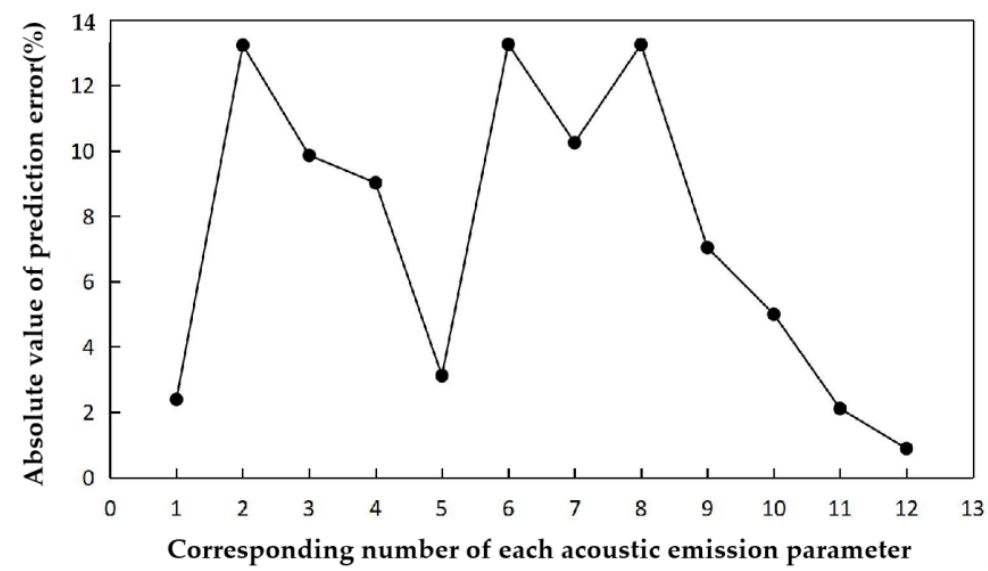

Figure 19. Single parameter (1-10), rise-time-amplitude (11), and multiparameter (12) absolute value of prediction error.

\section{Conclusions}

(1) In this work, six clustering algorithms were compared to find the best one to analyze the acoustic emission data of crumb rubber concrete. Based on the results and analysis provided, the density peak clustering algorithm is considered to be an optimal algorithm based on the reliability of its computational results.

(2) Therefore, the density peak clustering method was adopted to cluster the AE signals of the specimen and to investigate the variation of different damage modes during loading. The damage modes of concrete matrix fracture and rubber fracture correspond to peak frequencies of 40 and $100 \mathrm{kHz}$, respectively. Based on the results provided, combining $\mathrm{AE}$ technology with density peak clustering, the damage pattern identification of crumb rubber concrete could be carried out at a deeper level.

(3) For the prediction of the ultimate load of crumb rubber concrete, ten different acoustic emission parameter data were selected to establish an acoustic emission singleparameter artificial neural network prediction model. The prediction results of these ten single-parameter models were compared with the real values, and the prediction errors were calculated separately. Furthermore, five optimal acoustic emission parameter data were selected as the artificial neural network data input end to establish the acoustic emission multiparameter artificial neural network prediction model so as to predict the ultimate load. According to the results, the prediction error is only $0.89 \%$.

(4) These methods and conclusions adopted in this study are general and practical for the application and monitoring of crumb rubber concrete in practical engineering. However, some imperfections remain, and in the future, it will be necessary to estab- 
lish a deeper connection between AE parameters and other mechanical properties of crumb rubber concrete, as well as to explore newer and more efficient AE signal processing methods.

Author Contributions: Conceptualization, Z.F.; investigation, J.S.; writing, X.C.; supervision, G.L. All authors have read and agreed to the published version of the manuscript.

Funding: This research was funded by THE NATIONAL NATURAL SCIENCE FOUNDATION OF CHINA, grant number 51408408 and THE SPONSORSHIP GUARANTEED WITH BASIC RESEARCH FUNDS PROVIDED BY POLITECNICO DI TORINO (ITALY).

Institutional Review Board Statement: Not applicable.

Informed Consent Statement: Not applicable.

Data Availability Statement: The data presented in this article are available from the corresponding author upon request.

Conflicts of Interest: The authors declare no conflict of interest. The funders had no role in the design of the study; in the collection, analyses, or interpretation of data; in the writing of the manuscript, or in the decision to publish the results.

\section{List of Symbols}

$\begin{array}{ll}C_{i}^{(t)} & \text { Cluster } i \\ m_{i}{ }^{(t)} & \text { Center of cluster } i \\ m_{j}{ }^{(t)} & \text { Center of cluster } j \\ A_{n} & \text { Data points } \\ \partial & \text { Fuzzy coefficient } \\ \gamma_{i j} & \text { Membership value } \\ w_{k} & \text { Mixed weight function } \\ A & \text { Data points } \\ \mu_{k} & \text { Mean vector } \\ \sum_{k} & \text { Covariance matrix } \\ g(x) & \text { Gaussian density function } \\ W_{v} & \text { Weight vectors of the winning neuron } \\ u & \text { Evaluation parameter of neurons } \\ t & \text { Time } \\ \Theta(x) & \text { Neighborhood function } \\ r_{u} & \text { Locations of neurons } \mathrm{u} \\ r_{v} & \text { Locations of neurons } \mathrm{v} \\ \sigma(t) & \text { Width of the function } \Theta(x) \\ \rho_{i} & \text { Local density of data point } i \\ d_{i j} & \text { Distance between data points } i \text { and } j \\ d_{c} & \text { Cutoff distance } \\ \delta_{i} & \text { Distance from data point } i \text { to points of higher density } \\ S_{i} & \text { Weight of data point } i \text { as the clustering center } \\ & \end{array}$

\section{References}

1. Sathiskumara, C.; Karthikeyanb, S. Recycling of waste tires and its energy storage application of by-products-A review. Sustain. Mater. Technol. 2019, 22, e00125.

2. Adhikari, B.; De, D.; Maiti, S. Reclamation and recycling of waste rubber. Prog. Polym. Sci. 2000, 25, 909-948. [CrossRef]

3. Gnanaraj, J.; Lee, R.; Levine, A.; Wistrom, J.; Wistrom, S.; Li, Y.; Li, J.; Akato, K.; Naskar, A.; Paranthaman, M.P. Sustainable waste tire derived carbon material as a potential anode for lithium-ion batteries. Sustainability 2018, 10, 2840. [CrossRef]

4. Derakhshan, Z.; Ghaneian, M.T.; Mahvi, A.H.; Conti, G.O.; Faramarzian, M.; Dehghani, M. A new recycling technique for the waste tires reuse. Environ. Res. 2017, 158, 462-469. [CrossRef]

5. Li, N.; Long, G.; Ma, C.; Fu, Q.; Zeng, X.; Ma, K.; Xie, Y.; Luo, B. Properties of self-compacting concrete (SCC) with recycled tire rubber aggregate: A comprehensive study. J. Clean. Prod. 2019, 236, 117707. [CrossRef]

6. Gupta, T.; Chaudhary, S.; Sharma, R.K. Assessment of mechanical and durability properties of concrete containing waste rubber tire as fine aggregate. Constr. Build. Mater. 2014, 73, 562-574. [CrossRef] 
7. Gupta, T.; Sharma, R.K.; Chaudhary, S. Impact resistance of concrete containingwaste rubber fiber and silica fume. J. Mater. Civ. Eng. 2015, 83, 76-87.

8. Gupta, T.; Siddique, S.; Sharma, R.K.; Chaudhary, S. Effect of elevated temperature and cooling regimes on mechanical and durability properties of concrete containing waste rubber fiber. Constr. Build. Mater. 2017, 137, 35-45. [CrossRef]

9. Gupta, T.; Tiwari, A.; Siddique, S.; Sharma, R.K.; Chaudhary, S. Response assessment under dynamic loading and microstructural investigations of rubberized concrete. J. Mater. Civ. Eng. 2017, 29, 4017062. [CrossRef]

10. Yung, W.H.; Yung, L.C.; Hua, L.H. A study of the durability properties of wastetire rubber applied to self-compacting concrete. Constr. Build. Mater. 2013, 41, 665-672. [CrossRef]

11. Segre, N.; Joekes, I. Use of tire rubber particles as addition to cement paste. Constr. Build. Mater. 2000, 30, 1421-1425. [CrossRef]

12. Bisht, K.; Ramana, P.V. Evaluation of mechanical and durability properties of crumb rubber concrete. Constr. Build. Mater. 2017, 155, 811-817. [CrossRef]

13. Batayneh, M.K.; Marie, I.; Asi, I. Promoting the use of crumb rubber concrete in developing countries. Waste Manag. 2008, 28, 2171-2176. [CrossRef] [PubMed]

14. Kaloush, K.; Way, G.; Zhu, H. Properties of crumb rubber concrete. Transp. Res. Rec. J. Transp. Res. Board. 2005, 19, 8-14. [CrossRef]

15. Afshinnia, K.; Poursaee, A. The influence of waste crumb rubber in reducing the alkali-silica reaction in mortar bars. J. Build. Eng. 2015, 4, 231-236. [CrossRef]

16. Si, R.; Wang, J.; Guo, S.; Daiv, Q.; Han, S. Evaluation of laboratory performance of self-consolidating concrete with recycled tire rubber. J. Clean. Prod. 2018, 180, 823-831. [CrossRef]

17. Ganjian, E.; Khorami, M.; Maghsoudi, A.A. Scrap-tyre-rubber replacement for aggregate and filler in concrete. Constr. Build. Mater. 2009, 23, 1828-1836. [CrossRef]

18. Eldin, N.N.; Senouci, A.B. Measurement and prediction of the strength of rubberized concrete. Cem. Concr. Comp. 1994, 16, 287-298. [CrossRef]

19. Toutanji, H.A. The use of rubber tire particles in concrete to replace mineral aggregates. Cem. Concr. Comp. 1996, 18, 135-139. [CrossRef]

20. Fedroff, D.; Ahmad, S.; Savas, B.Z. Mechanical Properties of Concrete with Ground Waste Tire Rubber; Transportation Research Record No. 1532; Transportation Research Board: Washington, DC, USA, 1996.

21. Li, G.; Garrick, G.; Eggers, J. Waste tire fiber modified concrete. Compos. Part B Eng. 2004, 35, 305-312. [CrossRef]

22. Khaloo, A.R.; Dehestani, M.; Rahmatabadi, P. Mechanical properties of concrete containing a high volume of tire-rubber particles. Waste Manag. 2008, 28, 2472-2482. [CrossRef] [PubMed]

23. Joosten, M.W.; Dingle, M.; Mouritz, A.; Khatibi, A.A.; Agius, S.; Wang, C.H. A hybrid embedded cohesive element method for predicting matrix cracking in composites. Compos. Struct. 2016, 136, 554-565. [CrossRef]

24. Wu, J.Y.; Nguyen, V.P.; Zhou, H.; Huang, Y.L. A variationally consistent phase-field anisotropic damage model for fracture. Comput. Method. Appl. Mech. Eng. 2020, 358, 112629. [CrossRef]

25. Lin, P.; Wei, P.; Wang, C.; Kang, S.; Wang, X. Effect of rock mechanical properties on electromagnetic radiation mechanism of rock fracturing. J. Rock Mech. Geotech. Eng. 2021, in press. [CrossRef]

26. $\mathrm{Xu}$, J.; Fu, Z.; Han, Q.; Lacidogna, G.; Carpinteri, A. Micro-cracking monitoring and fracture evaluation for crumb rubber concrete based on acoustic emission techniques. Struct. Health Monit. 2018, 17, 946-958. [CrossRef]

27. Karunarathna, S.; Linforth, S.; Kashani, A.; Liu, X.; Ngo, T. Effect of recycled rubber aggregates size on fracture and other mechanical properties of structural concrete. J. Clean. Prod. 2021, in press. [CrossRef]

28. Mendis AS, M.; Al-Deen, S.; Ashraf, M. Flexural shear behaviour of reinforced Crumbed Rubber Concrete beam. Constr. Build. Mater. 2018, 17, 946-958. [CrossRef]

29. Tang, Y.C.; Feng, W.H.; Chen, Z.; Nong, Y.; Guan, S.H.; Sun, J.b. Fracture behavior of a sustainable material: Recycled concrete with waste. J. Clean. Prod. 2021, 318, 128553. [CrossRef]

30. Emadi, A.A.; Modarres, A. Impact of crumb rubber particles on the fracture parameters of concrete through WFM, SEM and BEM. Constr. Build. Mater. 2021, 305, 124693. [CrossRef]

31. Xu, J.; Yao, Z.Y.; Yang, G.; Han, Q.H. Research on crumb rubber concrete: From a multi-scale review. Constr. Build. Mater. 2020, 232, 117282. [CrossRef]

32. Shigeishi, M.; Colombo, S.; Broughton, K.J.; Rutledge, H.; Batchelor, A.J.; Forde, M.C. Acoustic emission to assess and monitor the integrity of bridges. Constr. Build. Mater. 2001, 15, 35-49. [CrossRef]

33. Jia, Y.; Tang, L.; Ming, P.; Xie, Y. Ultrasound-excited thermography for detecting microcracks in concrete materials. NDT E Int. 2019, 101, 62-71. [CrossRef]

34. Kim, G.; Loreto, G.; Kim, J.Y.; Kurtis, K.E.; Wall, J.J.; Jacobs, L.J. In situ nonlinear ultrasonic technique for monitoring microcracking in concrete subjected to creep and cyclic loading. Ultrasonics 2018, 88, 64-71. [CrossRef]

35. Tayfur, S.; Alver, N.; Abdi, S.; Saatc1, S.; Ghiami, A. Characterization of concrete matrix/steel fiber de-bonding in an SFRC beam: Principal component analysis and k-mean algorithm for clustering AE data. Eng. Fract. Mech. 2018, 194, 73-85. [CrossRef]

36. Thirumalaiselvi, A.; Sasmal, S. Pattern recognition enabled acoustic emission signatures for crack characterization during damage progression in large concrete structures. Appl. Acoust. 2021, 175, 107797. [CrossRef]

37. Abouhussien, A.A.; Hassan AA, A. Classification of damage in self-consolidating rubberized concrete using acoustic emission intensity analysis. Ultrasonics 2020, 100, 105999. [CrossRef] [PubMed] 
38. Calabrese, L.; Campanella, G.; Proverbio, E. Noise removal by cluster analysis after long time AE corrosion monitoring of steel reinforcement in concrete. Constr. Build. Mater. 2012, 34, 362-371. [CrossRef]

39. Thirumalaiselvi, A.; Sasmal, S. Acoustic emission monitoring and classification of signals in cement composites during early-age hydration. Constr. Build. Mater. 2019, 196, 411-427. [CrossRef]

40. Hartigan, J.A.; Wong, M.A. A k-Means clustering algorithm. Appl. Stat. 1979, 28, 100-108. [CrossRef]

41. Ciaburro, G.; Iannace, G.; Ali, M.; Alabdulkarem, A.; Nuhait, A. An artificial neural network approach to modelling absorbent asphalts acoustic properties. J. King Saud Univ. Sci. 2021, 33, 213-220. [CrossRef]

42. Han, Q.; Yang, G.; Xu, J.; Fu, Z.; Lacidogna, G.; Carpinteri, A. Acoustic emission data analyses based on crumb rubber concrete beam bending tests. Eng. Fract. Mech. 2019, 210, 189-202. [CrossRef]

43. Jain, A.K. Data clustering: 50 years beyond K-means. J. R. Stat. Soc. C 2010, 31, 651-666. [CrossRef]

44. Bezdek, J.C.; Ehrlich, R.; Full, W. FCM: The fuzzy c-means clustering algorithm. Comput. Geosci. 1984, 10, 191-203. [CrossRef]

45. Prabha, S.; Sujatha, C.M. Proposal of index to estimate breast similarities in thermograms using fuzzy C means and anisotropic diffusion filter based fuzzy C means clustering. Infrared. Phys. Technol. 2018, 93, 316-325. [CrossRef]

46. Saeedifar, M.; Najafabadi, M.A.; Zarouchas, D.; Toudeshky, H.H.; Jalalvand, M. Clustering of interlaminar and intralaminar damages in laminated composites under indentation loading using Acoustic Emission. Compos. Part B Eng. 2018, 144, 206-219. [CrossRef]

47. Vesanto, J.; Alhoniemi, E. Clustering of the self-organizing Map. IEEE Trans. Neural Netw. 2000, 11, 586-600. [CrossRef] [PubMed]

48. Murtagh, F. A survey of recent advances in hierarchical clustering algorithms. Comput. J. 1983, 26, 354-359. [CrossRef]

49. Rodriguez, A.; Laio, A. Clustering by fast search and find of density peaks. Science 2014, 344, 1492-1496. [CrossRef] [PubMed]

50. Sasikumar, T.; Rajendraboopathy, S.; Vasudev, K.M.U. Failure strength prediction of unidirectional tensile coupons using acoustic emission peak amplitude and energy parameter with artificial neural networks. Compos. Sci. Technol. 2009, 69, 1151-1155. [CrossRef]

51. Ganjefar STofighi, M. Training qubit neural network with hybrid genetic algorithm and gradient descent for indirect adaptive controller design. Eng. Appl. Artif. Intel. 2017, 65, 346-360. [CrossRef]

52. Canakci, A.; Varol, T.; Ozsahin, S. Artificial neural network to predict the effect of heat treatment, reinforcement size, and volume fraction on AlCuMg alloy matrix composite properties fabricated by stir casting method. Int. J. Adv. Manuf. Technol. 2015, 78, 305-317. [CrossRef]

53. Sasikumar, T.; Rajendraboopathy, S.; Usha, K.M.; Vasudev, E.S. Artificial neural network prediction of ultimate strength of unidirectional T-300/914 tensile specimens using acoustic emission response. J. Nondestr. Eval. 2008, 27, 127-133. [CrossRef]

54. Rousseeuw, P.J. Silhouettes: A graphical aid to the interpretation and validation of cluster analysis. J. Comput. Appl. Math. 1987, 20, 53-65. [CrossRef]

55. Ohtsu, M. Acoustic emission characteristics in concrete and diagnostic applications. J. Acoust. Soc. Am. 1987, 6, 99-108.

56. Li, Z.; Shah, S.P. Localization of micro-cracking in concrete under uniaxial tension. ACI Mater. J. 1994, 91, 372-381. 